Invited Review: Research Update

\title{
Regulation of human (adrenal) androgen biosynthesis - new insights from novel throughput technology studies
}

Running title: Update on human androgen synthesis and regulation

Sameer S. Udhane and Christa E. Flück

Pediatric Endocrinology and Diabetology of the Department of Pediatrics and Department of Clinical Research, University of Bern, 3010 Bern, Switzerland

Address of corresponding author:

Christa E. Flück

Pediatric Endocrinology and Diabetology

University Children's Hospital Inselspital

Freiburgstrasse 15 / C845

3010 Bern

Switzerland

Phone: +41316320499

Email: christa.flueck@dkf.unibe.ch 


\section{Abstract}

Androgens are precursors for sex steroids and are predominantly produced in the human gonads and the adrenal cortex. They are important for intrauterine and postnatal sexual development and human reproduction. Although human androgen biosynthesis has been extensively studied in the past, exact mechanisms underlying the regulation of androgen production in health and disease remain vague. Here, the knowledge on human androgen biosynthesis and regulation is reviewed with a special focus on human adrenal androgen production and the hyperandrogenic disorder of polycystic ovary syndrome (PCOS). Since human androgen regulation is highly specific without a good animal model, most studies are performed on patients harboring inborn errors of androgen biosynthesis, on human biomaterials and human (tumor) cell models. In the past, most studies used a candidate gene approach while newer studies use high throughput technologies to identify novel regulators of androgen biosynthesis. Using genome wide association studies on cohorts of patients, novel PCOS candidate genes have been recently described. Variant 2 of the DENND1A gene was found overexpressed in PCOS theca cells and confirmed to enhance androgen production. Transcriptome profiling of dissected adrenal zones established a role for BMP4 in androgen synthesis. Similarly, transcriptome analysis of human adrenal $\mathrm{NCl}-\mathrm{H} 295$ cells identified novel regulators of androgen production. Kinase p38a (MAPK14) was found to phosphorylate CYP17 for enhanced 17,20 lyase activity and RARB and ANGPTL1 were detected in novel networks regulating androgens. The discovery of novel players for androgen biosynthesis is of clinical significance as it provides targets for diagnostic and therapeutic use. 


\section{Current knowledge of human androgen biosynthesis}

Androgens are steroids that are able to stimulate the androgen receptor and thereby promote masculine (Greek andros - male) effects. In addition, androgens are the precursors of all estrogens. Testosterone is the best known human androgen, who's activity is essential during fetal development to form the complete normal male phenotype in a $46, \mathrm{XY}$ fetus. On the other hand, a 46,XX female fetus will encounter virilization of the external genitalia and the brain under the influence of high androgen levels. Beyond infancy and childhood, normal androgen synthesis is needed for pubertal development, sexual life and fertility in both males and females. Thus, biosynthesis of human androgens must be tightly regulated during fetal and postnatal life. Among all vertebrates, androgen production is also regulated in a species-, sex-, organ- and mostly cell-specific manner. However, its regulation is still not fully understood. Common human disorders that are associated with deregulated androgen production include premature adrenarche, polycystic ovary syndrome (PCOS) and prostate cancer. The treatment of these hyperandrogenic states awaits improvement. However, to optimize the treatment it is crucial to understand androgen regulation in health and disease in great detail. This review aims to summarize the recent gains in knowledge of human androgen production and regulation with a special focus on human adrenal androgens and PCOS. We also allowed ourselves to include our own recent work and put it into the context of current (ongoing) research in the field.

\subsection{Biochemistry of androgen biosynthesis}

\subsubsection{The classic pathway of testosterone synthesis}

All steroids (not only androgens and estrogens, but also mineralocorticoids and glucocorticoids) are produced from a cholesterol precursor, which is transported to the inner mitochondrial membrane with the help of the steroidogenic acute regulatory protein (StAR) (Figure 1) [1]. At the inner mitochondrial membrane the first and rate limiting step of the steroid cascade is supported by the so-called side-chain cleavage system consisting of the enzyme CYP11A1 and 
its cofactors ferrodoxin and ferrodoxin-reductase, yielding pregnenolone (Preg) as a conversion product. For testosterone production through the classic pathway, Preg is then converted in a stepwise manner to 17-hydroxypregnenolone (17OH-Preg) and dehydroepiandrosterone (DHEA) by the 17-hydroxylase and 17,20 lyase activities of CYP17 supported by cofactors P450 oxidoreductase (POR) and cytochrome b5 (CYB5). DHEA is a C19 steroid and androgen precursor, which is then either converted to androstenedione $(\Delta 4 \mathrm{~A})$ or androstenediol and finally to testosterone by the enzymes $3 \beta$-hydroxysteroid dehydrogenase (HSD3B) and 17 $\beta$ hydroxysteroid dehydrogenase (HSD17B), which both come in different isozymes with tissuespecific expression [1]. 5a-reductase (SRD5A) can then convert Testosterone to the most potent androgen, the dihydrotestosterone (DHT). Concerning androgen action on the androgen receptor $(\mathrm{AR})$ for biological effects, $\mathrm{DHT}$ is the most potent androgen followed by testosterone, while $\triangle 4 \mathrm{~A}$ and androstenediol exert only weak activation of the AR [2]. By contrast, DHEA does not bind to the AR, and is therefore only an androgen precursor [3].

\subsubsection{The novel, alternative "backdoor" pathway}

The existence of an alternative pathway to DHT synthesis was first discovered in the tammar wallaby pouch young, then in mice pups [4-6] (Figure 1). Specific steroid metabolites of this alternative pathway were then found in humans harboring steroid biosynthetic defects due to POR deficiency [7, 8], and later also in patients with congenital adrenal hyperplasia due to 21 hydroxylase (CYP21A2) deficiency [9]. Finally, we identified human genetic mutations in specific genes (aldo-keto reductase family 1 , member C2/4 (AKR1C2/4)) of this novel pathway in 46,XY individuals with moderate to severe forms of disordered sex development (DSD) [10]. Although this pathway seems to play a role in human sex differentiation during fetal life, its postnatal role remains largely unknown. This pathway is currently thought to diverge from the classic pathway at the level of the 17-hydroxyprogesterone (17OH-Prog) and proceed through $17 \mathrm{OH}$ dihydroprogesterone (17OH-DHP; 5a-pregnane-17a-ol-3,20-dione), 17OH-allopregnanolone 
(17OH-Allo; 5a-pregnane-3a,17a-ol-3,20-dione), androsterone and androstanediol (3aDiol) to DHT. The stepwise conversion of $170 \mathrm{H}-$ Prog to DHT is supported by the enzymes $5 \alpha-$ reductase type 1 (SRD5A1), AKR1C2/4, CYP17, HSD17B3/5 and AKR1C2/4 or HSD17B6 (Figure 1) $[6,11]$.

\subsection{Organ specific androgen production}

Androgen production is specific for species, sex, during development as well as between organs and tissues. To enable such complex specificity, enzyme activities for androgen synthesis are tightly regulated by various mechanisms including epigenetic, transcriptional, posttranscriptional and posttranslational regulation as well as substrate and cofactor availability. So far, tissue- and cell-specific androgen production seems largely regulated by specific expression of genes for steroid enzymes. However, many aspects of androgen regulation remain obscure, and little to nothing is known about the backdoor pathway of androgen synthesis.

\subsubsection{Gonads (testis/ovary)}

In the adult human testis, the Leydig cell produces testosterone from cholesterol through the classic pathway of androgen synthesis (Figure 1 and 2). For that, human testosterone synthesis predominantly follows the so-called delta 5 pathway from Preg to 170 HPreg to DHEA and then $\triangle 4 \mathrm{~A}$ and testosterone (Figure 1) [12], and the Leydig cell specifically expresses the isozymes HSD3B2 and HSD17B3 [1]. By contrast, testosterone synthesis in the testis of rodents occurs predominantly through the delta 4 pathway from Preg to progesterone (Prog) to $17 \mathrm{OH}$-Prog, then $\triangle 4 \mathrm{~A}$ and testosterone [13-15]. Differences in the use of the delta 5 and/or delta 4 pathway for testosterone synthesis are explained by variable catalytic efficiencies for the 17,20 lyase reactions between species. Testosterone production in the testis is confined to the Leydig cell, from which it is secreted. But testosterone is not only a hormonal regulator, it also exerts intratesticular effects on Sertoli cells and spermiogenesis. In principal, luteinizing hormone (LH) 
of the pituitary gland, which is under the control of the hypothalamic gonadotropin releasing hormone $(\mathrm{GnRH})$ controls testosterone synthesis in the Leydig cell. The Leydig cell also secretes small amounts of $\Delta 4 \mathrm{~A}$ and estradiol. Tiny amounts of estradiol are also produced from androgens in immature Sertoli cells and developing sperm cells, which both express CYP19A1 (aromatase) [16]. Whether the alternative backdoor pathway for DHT synthesis plays a role in the adult testis is unknown, but its involvement in fetal testicular androgen production has been shown in the context of human mutations [10].

The adult human ovary produces Prog and estradiol from cholesterol in a collaborative two-cell system in a cycle specific pattern under the control of gonadotropins $\mathrm{LH}$ and FSH. Prog is produced during the luteal phase and estradiol during the follicular phase. Since the granulosa cell lacks CYP17A1, it converts cholesterol to Preg (by CYP11A1), which is then converted either to Prog (by HSD3B2) or transferred to the theca cell for the production of $\triangle 4 \mathrm{~A}$ by CYP17/POR/CYB5 and HSD3B2. Little $\triangle 4 \mathrm{~A}$ is converted to testosterone likely through HSD17B5/AKR1C3. However, most $\triangle 4 \mathrm{~A}$ is transferred back to the granulosa cell, which expresses aromatase (CYP19A1) and HSD17B1 specifically for the synthesis of estradiol. During normal sex steroid production in the gonads some leakage of metabolites to the periphery occurs. $\Delta 4 \mathrm{~A}$ leakage from theca cells comprises about $50 \%$ of circulating androgens in women [17]. In men, circulating estrogens, which represent a fraction of 1/200 of androgens, originate by about $60 \%$ from the testes either directly or indirectly $[18,19]$.

\subsubsection{Adrenal androgens}

The adult human adrenal cortex is composed of three layers, namely the zona glomerulosa $(Z G)$ for mineralocorticoid production, the zona fasciculata (ZF) for glucocorticoid production and the zona reticularis $(\mathrm{ZR})$ for androgen production. In contrast to the $\mathrm{ZG}$ and $\mathrm{ZF}$, which replace the fetal adrenal soon after birth, the ZR is only slowly formed over the course of the first years of life and becomes functionally active after the age of 6-8 years at adrenarche [20]. 
Development of the adrenal zones is thought to involve centripetal differentiation of progenitor cells into ZR, then ZG and finally ZR cells [21]. The ZR attains full activity in terms of androgen production at around 30 years and declines in activity thereafter [22]. The characteristics of the ZR are high CYP17-17,20 lyase, low HSD3B2 and high sulfonyl-transferase (SULT2A1) activities yielding massive production of DHEA and DHEA-sulfate (DHEA-S) and some $\triangle 4 \mathrm{~A}$ (Figure 1) [23]. A similar steroid biosynthetic profile is found in the fetal zone of the adrenals during intrauterine life, but fetal adrenals involute soon after birth. The physiologic role of fetal DHEA production is unknown. Fetuses without adrenal function develop normally and survive to term [24]. Also, fetal DHEA is immediately metabolized to estrogens by the fetal-placental unit since otherwise elevated DHEA may lead to abnormal virilization of the external genitalia in a female fetus. Similarly, the physiologic role of the ZR and its androgen production remain unknown. Moreover, adrenarche is a phenomenon observed in humans and higher primates only and is not found in rodents [25]. However, premature adrenarche and exaggerated adrenal androgen production may be regarded as pathologic states, since they often lead to PCOS in later life $[26,27]$. In healthy women, adrenal androgens contribute about $50 \%$ to the pool of circulating androgens [17].

\subsubsection{Peripheral androgen synthesis and metabolism}

In general, circulating (precursor) androgens may be substrates for the synthesis of more potent androgens in extra-adrenal and extra-gonadal tissues [28]. Thus DHEA/-S and $\triangle 4 A$ may be converted to testosterone in peripheral tissues that express HSD3B1 and HSD17B1/5, such as the adipose tissue or the skin (Figure 2). These steroids may be further converted to estrogens in the periphery, e.g. by aromatase activity in the adipose tissue (Figure 2). For instance, the pilosebaceous unit of the skin is equipped with the enzymatic machinery to produce both androgens and estrogens, either in small amounts directly from cutaneous cholesterol or, in larger amounts, from circulating androgen precursors [29]. Most importantly, the skin expresses 
SRD5A1 abundantly for the conversion of testosterone to DHT, which cannot be further aromatized to estrogens.

Most steroids are metabolized in the liver to make them water-soluble. Through this process many active and inactive metabolites arise of known and unknown biological function. Finally, over $99 \%$ of all steroids are excreted through the kidney in the urine. Therefore, studying urine steroids provides an opportunity to obtain a global idea of endogenous steroid biosynthesis and metabolism and offers a great opportunity for diagnostics [30].

\section{Disorders of human androgen biosynthesis}

\subsection{Hypoandrogenism}

Low androgen levels or lack of androgens lead to disorders in both sexes. Causes for hypoandrogenism are manifold such as genetic, environmental (e.g. toxins or drugs) or acquired (e.g. organ loss), and may be at the level of the producing organ (primary) or at the level of organ stimulation (secondary) by hypothalamic-pituitary hormones (e.g. corticotropin-releasing hormone $(\mathrm{CRH})$ - adrenocorticotropic hormone $(\mathrm{ACTH})$ for adrenal steroids and $\mathrm{GnRH}$ $\mathrm{LH} /$ follicle-stimulating hormone (FSH) for gonadal steroids). In general, lack of androgens manifests more severely in males than females since androgens are essential for the development of the male phenotype and physiologically needed hormone levels are much higher in males than females. Therefore, genetic defects of androgen biosynthesis or action lead from mild to severe forms of disorders of sex development in chromosomal males, known as 46,XY DSD. Such defects (e.g. mutations in StAR, CYP11A1, HSD3B2, CYP17A1 or POR) may be associated with life-threatening adrenal insufficiency requiring glucocorticoid and maybe mineralocorticoid replacement therapy for survival [31, 32]. Genes involved in 46,XY DSD and defective androgen biosynthesis only include CYB5, HSD17B3, SRD5A2 and AKR1C2/4. In addition, androgen deficiency in males leads to lack of pubertal development and reproductive functions. Similarly, as all estrogens are produced from androgen precursors, some androgen 
biosynthetic defects also affect sex steroid production in females leading to lack of pubertal development, menstrual cycles and thus fertility (e.g. StAR, CYP11A1, HSD3B2, CYP17A1, POR).

In principal, genetic defects affecting androgen biosynthesis are known for all genes of the classic and some genes of the alternative, backdoor pathway (Figure 1). We have recently reviewed these genetic disorders and their phenotype in great detail [31].

\subsection{Hyperandrogenism}

In adulthood, androgen excess is less of a concern in males than in females. Hormonally active tumors of the testis or the prostate (or the adrenal cortex) and drug abuse are clinically most relevant in adult males. By contrast, androgen excess during infancy and childhood may lead to precocious pseudopuberty and growth acceleration in boys and girls, and is mostly due to genetic defects (e.g. mutations in the CYP21A2 gene) causing non-classic congenital adrenal hyperplasia. However, although rarer, androgen excess in childhood may also be found with tumors of the adrenal cortex or the testis. In females, androgen excess especially during early pregnancy, may result in moderate to severe virilization of the external genitalia (also known as 46,XX DSD). Milder signs of virilization (cliteromegaly, acne and hirsutism) may also occur postnatally under the influence of androgens. More important however in females is that androgen overproduction will lead to amenorrhea and thus infertility. The most common genetic steroid biosynthesis disorder leading to androgen excess is congenital adrenal hyperplasia due to 21-hydroxylase deficiency, but other genes may also cause 46,XX DSD (e.g. HSD3B2, CYP11B1, POR, CYP19A1) [24]. In childhood, the most common disorder of androgen excess is premature adrenarche, which is defined as the awakening of the adrenal ZR function before the age of 8 years. Premature adrenarche is visible as the premature appearance of pubic and/or axillary hair, oily skin and stinky feet. Epidemiologic studies suggest that premature adrenarche may lead to PCOS in later life [27] and therefore be regarded as risk factor or even 
early manifestation of PCOS. PCOS is the most common androgen excess syndrome in adult life affecting $5-10 \%$ of women. PCOS is defined by androgen excess, menstrual disorders and polycystic ovaries [33]. In PCOS both, the ovaries and the adrenal cortex contribute to excessive androgen production [34]. Although PCOS comprises a large health burden, treatment options are very limited because its pathophysiology is poorly understood. Currently, two hypotheses are discussed in the scientific community: In one hypothesis key to the underlying defect seems to be insulin resistance, while in the other hypothesis androgen excess plays an important role [35]. Given that PCOS manifests with different phenotypes, different underlying pathomechanisms in a connected biological network may be expected. Treatment of PCOS is currently symptomatic with common drugs targeting the reproductive and/or metabolic consequences of the disorder, e.g. oral contraceptives for menstrual irregularities and metformin for pathologic glucose tolerance [36].

\section{Models to study androgen production}

\subsection{Experiments of nature in humans}

Clinical, biochemical and genetic studies of patients presenting with inborn errors of androgen biosynthesis have contributed essentially to our current knowledge of androgen production and regulation. To date, human genetic mutations are described for almost all genes involved in androgen synthesis (Figure 1 and [24]). The latest mutations identified in subjects with 46,XY DSD due to a defect in androgen synthesis were found in the backdoor pathway [10]. In addition, genome-wide association studies (GWAS) in large cohorts of PCOS patients have recently provided novel candidate genes, which were hitherto out of focus [37, 38]. Follow-up studies of one of those genes, DENN/MADD domain containing 1A (DENND1A), revealed that variant 2 of this gene is an important regulator of androgen biosynthesis [39]. Furthermore, clinical studies in offspring of mothers with PCOS or their parents have revealed insight into the heritability and the evolution of the syndrome [40-42]. Thus, clinical studies of affected subjects 
and analysis of their biomaterials have been and will always be of outmost importance to understand disease mechanisms and treatment effectiveness.

\subsection{Tissue and cell models for studying androgen biosynthesis}

Models to study the regulation of androgen biosynthesis of the human adrenal cortex and the ovary, when interested in premature adrenarche and PCOS, are scarce. In general, no good small animal models are available as steroid biosynthesis is highly species-specific, and studies using higher primates, which resemble the human system, are rightfully very restricted.

Studies in sheep or rhesus monkeys have revealed that fetuses, which were exposed to high concentrations of androgens in utero, developed a PCOS-like phenotype postnatally, indicating that the syndrome is due to abnormal androgen programming during development and may not only be caused by endogenous (genetic), but also exogenous (environmental) factors [43].

Obtaining "fresh" human ovarian tissue, which is steroidogenically active and therefore originating from women during their fertile years, is understandably rare to obtain. In addition, establishing primary cultures from ovarian tissue will only generate a very short lived culture model as steroid production has been shown to cease after 4-6 days in culture [44]. Only the McAllister laboratory is successfully performing studies on human androgen producing theca cells originating from ovaries of healthy and PCOS women who donated leftover cell material for scientific use during invasive fertility procedures [45]. However, current fertility procedures no longer produce such byproducts. In addition, no immortalized tumor cell line exists for studying theca cell steroidogenesis and available granulosa tumor cell lines may not suffice to address the biology of ovarian androgen production, because these cells do not express CYP17 for androgen biosynthesis [46]. Human granulosa cells used for in vitro studies mainly originate from patients donating biomaterial whilst undergoing in vitro fertilization (IVF). These women and thus their granulosa cells have been stimulated with $\mathrm{FSH}$ and human chorionic gonadotropin (hCG). The isolated granulosa cells are therefore fully luteinized and have a 
limited life span in vitro [47]. Although it has been also challenging to establish primary cultures of granulosa cells, unlike for theca cells, there are several granulosa cell lines established from various species including rodent, bovine, porcine and primate [46]. These cell lines have been developed with different methods such as spontaneous immortalization, oncogenic transformation, chemical mutagenesis, explants of human tumors, and tumorigenesis in transgenic animal models [46]. In the past, we have tried to develop a primary cell culture model consisting of mixed granulosa and theca cells from pig ovaries (unpublished data). But cell cultures showed steroid biosynthesis only during the first 2-3 passages and the steroid profile did not reflect physiological values/ circumstances since CYP17 activity was minimal.

Furthermore, there is no proper human testicular Leydig cell model to study human androgen biosynthesis. Though, some rodent Leydig cell models like mouse Leydig MA-10 cells exist, these cells cannot be used as a model to study human androgen production since the androgen biosynthesis pathway varies between humans and rodents $[12,48]$.

Similarly, models for studying human adrenal androgen biosynthesis are also limited: firstly, adrenal androgen production and zonation differs profoundly between various species such that a rodent model may not be used to address questions concerning human adrenal steroidogenesis [49,50]; second, adrenarche is a phenomenon limited to humans and few higher primates (chimpanzees, gorillas and orangutans) [51, 52]. Therefore, current studies investigating adrenal androgen synthesis use tissue material originating from the human adrenal cortex or derived cell cultures. Tissue material has been employed for immunohistochemical studies [53] or gene expression studies [54-56], but is difficult to use for functional studies. Thus far, all attempts to establish a human primary cell line from the human adrenal cortex have remained unsuccessful [57], but decades ago an immortalized cell line NCl-H295 was established from an adrenocortical carcinoma tumor harboring characteristics of all three zones 
of the adrenal cortex [58]. Since then two adherent strains of this cell line (H295R (ATCC; CRL2128) and H295A [59] are almost exclusively used for functional studies of human adrenal steroidogenesis. Although the two cell lines originated from the same tumor, they differ. H295A cells produce more mineralocorticoids, whereas H295R cells produce more androgens likely due to lower HSD3B2 but higher CYP17-17,20 lyase activity [60]. This "androgenic" character makes H295R cells a good model to study androgen biosynthesis, even more so since their androgen production may be enhanced by starvation growth conditions [61].

\section{Knowledge gain using the old candidate gene or hypothesis driven approach}

In the past, researchers have mostly used a candidate gene or hypothesis driven approach to study synthesis and regulation of androgens. In the following section, we will show recent contributions that were obtained in the field using this approach.

\subsection{Regulation of specific genes involved in androgen production}

CYP17 and HSD3B2 are essential for androgen biosynthesis (Figure 1) and therefore studies of their regulation are key to understanding androgen over- or underproduction.

\subsubsection{CYP17}

The CYP17 enzyme (localized in the endoplasmic reticulum) possesses 17a-hydroxylase and 17,20 lyase activities (Figure 1). In the human adrenal cortex CYP17 is expressed in the ZF and the ZR enabling glucocorticoid and androgen synthesis, but only androgen production requires both hydroxylase and lyase activities. Lyase activity of CYP17 is supported in the ZR by at least three factors. First, the amount of POR for electron transfer [62], second, presence of allosteric activator microsomal CYB5 [63], and third, phosphorylation of the CYP17 protein at serine residues $[61,64,65]$. Protein phosphatase 2A (PP2A) was shown to dephosphorylate CYP17 and diminish lyase activity and androgen synthesis [66]. Although phosphorylation of CYP17 
has been shown to be enhanced by cyclic adenosine monophosphate (cAMP)/protein kinase A (PKA) [64, 65], and rho-associated, coiled-coil containing protein kinase 1 (ROCK1), this phosphorylation does not increase lyase activity [67]. Only recent studies identified the mitogenactivated protein kinase 14 (MAPK14, p38a) as the responsible kinase enhancing 17,20 lyase activity by phosphorylation [68]. In line with this finding, involvement of the mitogen-activated protein kinase (MEK) and the extracellular signal-regulated kinase (ERK) signaling was also reported for the hyperandrogenic state of PCOS theca cells [69], and for the mechanism of action of the drug pioglitazone in down regulating androgen production in H295R cells [70].

Given the key role of CYP17 in androgen production, finding specific CYP17 inhibitors for clinical use is of great interest. Abiraterone is a CYP17 inhibitor already in use for prostate cancer treatment but unfortunately it also alters activities of other CYP enzymes [71, 72]. Therefore, with new drug development strategies more selective CYP17-17,20 lyase inhibitors are currently designed and being tested (e.g. orteronel, galeterone and VT-464).

\subsubsection{HSD3B2}

In humans, there are two HSD3B isozymes, which share $93.5 \%$ identity at the protein level, have the same function in steroidogenesis, but show tissue specific expression [73, 74]. HSD3Bs are membrane bound enzymes, which reside in the mitochondrion or the ER depending on the cell type they are expressed in [74, 75]. HSD3B2 is exclusively expressed in the adrenal cortex and the gonads. During adrenarche the gene expression profile of the ZR changes; the expression of CYP17, CYB5 and POR increases while the expression of HSD3B2 decreases [20, 76, 77]. By contrast, with PCOS expression of both CYP17 and HSD3B2 increases in the theca cells compared to controls [78], indicating that androgen regulation differs in various situations.

As shown in cell based studies, transcription factors like nerve growth factor IB (NGFIB/Nur77), GATA and steroidogenic factor-1 (SF-1)/liver receptor homologue 1 (LRH1) seem essential for 
regulating HSD3B2 $[79,80]$. Nur77 plays an important role for HSD3B2 expression during fetal development [81] and adrenal zonation [82]. We found differential regulation of HSD3B2 under serum starvation and CAMP stimulation conditions [79]. Short cyclic AMP stimulation inhibits HSD3B2 activity while long CAMP stimulation enhances HSD3B2 expression and activity [79]. Further studies revealed that PKA and MEK/ERK signaling are involved in modulating HSD3B2 [79], but the exact network regulating HSD3B2 for androgen synthesis remains unknown. However, it is reported that membrane translocase Tim50 protein regulates HSD3B2 expression and activity, implying a role for translocases in steroidogenesis [83]. Additionally, other factors like $\mathrm{pH}$ have also been reported to modulate HSD3B2 conformation and thus enzyme activity [84].

\subsection{Role of specific signaling pathways for androgen regulation}

A complex network with cross talks between multiple signaling pathways appears to modulate androgen production (Figure 3) $[85,86]$. Accordingly, androgen excess and PCOS may be caused by various defects within this network, but only a few pathways are known to be involved. With regard to androgen production, the adrenocorticotropic hormone $(\mathrm{ACTH}) / \mathrm{CAMP} / \mathrm{PKA}$ and the Mitogen-activated protein kinase (MAPK) signaling are most widely studied.

\subsubsection{Androgen regulation and the ACTH/CAMP/PKA pathway}

ACTH stimulates adrenal glucocorticoid biosynthesis and co-regulates adrenal androgen production [20, 87]. ACTH is also a developmental and growth factor for the adrenal cortex [88]. It binds to the melanocortin 2 receptor (MC2R) at the cell surface, which is a G-protein coupled receptor (GPCR) that triggers the production of the second messenger cAMP [85, 89]. Likewise, FSH and LH stimulate sex steroid biosynthesis in the gonads by binding to their specific 
GPCRs, production of CAMP and activation of the PKA signaling leading to phosphorylation of various proteins and transcription factors involved in androgen synthesis [85]. Although the cAMP/PKA signaling seems to play an important role, second messenger cAMP can also cross talk to other signaling pathways such as MEK/ERK to target CYP17 and HSD3B2 [69, 79].

\subsubsection{Androgen production and the MAPK pathway}

Mitogen-activated protein kinases (MAPKs) are serine/threonine kinases. In mammalian cells, the MAPK family comprises four major groups: 1) mitogen-activated protein kinase $1 / 2$ (MEK1/2)/ extracellular signal-regulated kinase 1/2 (ERK1/2), 2) p38MAPKs, 3) c-Jun Nterminal kinases/stress-activated protein kinases (JNK/SAPKs), and 4) extracellular signalregulated kinase 5 (ERK5) [90]. MAPKs transmit signals from a large array of extracellular stimuli such as growth factors, hormones, cytokines and neurotransmitters. So far MEK/ERK1/2 and p38MAPKs signaling has been reported to being involved in the regulation of androgen production [48, 68-70, 91]. Inhibition of MEK/ERK signaling affects CYP17 and HSD3B2 expression and thus androgen synthesis [61, 79]. Recently, we showed that under hyperandrogenic starvation conditions, kinases MEK and ERK were less phosphorylated in H295R cells [48, 86]. This finding fits with the report that phosphorylation and activity of MEK/ERK kinases are decreased in hyperandrogenic PCOS theca cells [69]. On the other hand, kinase p38a has recently been shown to phosphorylate CYP17 for enhanced 17,20 lyase activity and thus production of androgens [68].

\subsubsection{Other signaling pathways involved in androgen production}

In a recent review we published some preliminary results establishing a possible role for protein kinase $C(P K C)$ and protein kinase $D(P K D)$ signaling in androgen production [86]. Studies for phosphoinositide-3-kinase $(\mathrm{PI} / \mathrm{K})$ /protein kinase $\mathrm{B}$ (PKB/Akt) signaling revealed mixed results $[67,86]$, so that its role remains unsolved. Additionally, non-GPCR and non-cAMP-dependent 
signaling pathways were found to influence androgen biosynthesis [85]. Stimulators of such pathways include growth factors like insulin-like growth factor-1(IGF-1), epidermal growth factor (EGF), steroidogenic-inducing protein (SIP), macrophage derived factors and chloride or calcium channel messengers [85]. In Leydig cells and adrenal cells, growth factors EGF and IGF-1/insulin have been shown to regulate steroidogenesis [88, 92].

\section{New(er) approaches: high throughput techniques}

The major problem with using a candidate gene or hypothesis driven approach for studying disease mechanisms is that the unknown or unthought of possibilities are left out. Hence, the candidate based approach is useful when strong candidates are available. By contrast, to find novel candidates regulating human androgen biosynthesis, which are out of focus of current thinking, high throughput approaches like GWAS and transcriptome profiling may be used (or: are a good alternate option).

\subsection{GWAS to solve PCOS}

PCOS seems to be a complex disorder caused by environmental (e.g. obesity) as well as genetic factors [93]. It has a high incidence in different populations and puts family members at risk of also developing PCOS [94, 95]. Recent GWAS on large PCOS cohorts revealed several loci suggesting that inheritance of PCOS is likely multifactorial [37, 38, 96-98]. Two GWAS studies on large cohorts of Han Chinese people identified a total of 11 loci and revealed the following genes associated with PCOS: thyroid adenoma associated (THADA), DENND1A, insulin receptor (INSR), follicle-stimulating hormone receptor (FSHR), luteinizing hormone/choriogonadotropin receptor (LHCGR), high mobility group AT-hook 2 (HMGA2), Yesassociated protein 1 (YAP1), chromosome 9 open reading frame 3 (C9orf3), TOX high mobility group box family member 3 (TOX3), Ras-related protein Rab-5B (RAB5B) and SUMO1 pseudogene 1 (SUMO1P1)/zinc finger protein 217 (ZNF217) [37, 38]. Importantly, these 
candidate genes were also identified in GWAS of PCOS women in the European population [96, $97,99,100]$.

One of these candidates, DENND1A was recently further explored and confirmed to cause PCOS [39]. Through alternative splicing the DENND1A gene yields two principal transcripts, namely DENND1A variant 1 (DENND1A.V1) and variant 2 (DENND1A. V2). Both variants harbor clathrin-binding domains but possess distinct C-terminal domains and therefore interact differentially with membrane adaptor proteins [51]. DENND1A is highly expressed in androgen producing tissues [98]. McAllister et al. reported just recently that expression of DENND1A variant 2 is increased in PCOS theca cells, while variant 1 is decreased compared to normal theca cells [39]. They showed that overexpression and knockdown of DENND1A.V2 in normal theca cells altered CYP17 and CYP11A1 gene transcription and androgen production accordingly, but the exact mechanism of action for connecting DENND1A to androgen synthesis remains unclear. DENND1A.V2 perhaps alters the signaling to steroidogenesis via gonadotropin or insulin receptors [101]. Nuclear localization of DENND1A.V2 suggests that it modulates gene transcription or that it functions as scaffold for transcription factors that regulate gene expression of steroidogenic enzymes. Current interest in DENND1A.V2 includes whether it might be used as a diagnostic marker for PCOS, and whether it could be a target for future treatment.

Besides DENND1A, loci harboring receptors LHCGR, FSHR and INSR have also been identified and replicated in GWAS studies in several PCOS cohorts [96, 97]. These receptors are activated by LH, FSH and insulin and their involvement in controlling follicular growth, differentiation and ovarian steroidogenesis is established [102-105]. 


\subsection{Tissue transcriptome profiling}

Tissue profiling has been shown to be a powerful tool for basic and translational research as well as for diagnostic applications and drug discovery [106]. Through the use of transcriptome analysis, new information may be generated on (physiologic) mechanisms, pathways and genes involved in specific biologic processes.

Several studies have addressed the specific development and function of the fascinating zonation of the adrenal cortex both in humans and other mammals, but so far many aspects remain unrevealed. This is particularly true for the ZR, which develops continuously after birth and produces adrenal androgens in a life-time specific fashion that is found similarly only in higher primates [25]. However, it is key to understand these regulations for the development of new treatment strategies against hyperandrogenic disorders such as premature adrenarche and PCOS.

In the past, remarkable knowledge on adrenal zonation and function was gained through (immune) histological and biochemical studies. Already in 1996 Endoh et al [107] isolated ZF and ZR cells from the human adrenal cortex and demonstrated that the ZR in comparison to ZF secretes large amounts of DHEA due to little expression of HSD3B2. Wang et al [54] described in 2001 the differential gene expression profiles of the human ZR and ZF using RNA isolation and cDNA hybridization on a microarray. He found that 17 of the 750 genes included in the array differed in expression by more than 2-fold; among them were transcripts of HSD3B2, aldoketo reductase family 1 , member B1 (AKR1B1) and SULT2A1. Meanwhile several gene expression studies, were performed on rodent tissues and cells [108-110]. However, with these studies questions on human ZR may not be addressed since rodents do not have a functional ZR $[49,50,111]$. Only recently transcriptome profiling of the human adrenal ZF and ZR was repeated with an array containing 47,231 transcripts of the human genome [55]. In this study, expression of 347 genes varied by 2 -fold between ZF and ZR. Interestingly, in the group of steroidogenic enzymes, only HSD3B2, SULT2A1, AKR1C3 and CYB5 were significantly 
different, with HSD3B2 being less and the other three genes being more highly expressed in the ZR [55]. Using this unbiased method, novel players were identified including a network containing bone morphogenetic proteins (BMPs) (e.g. BMP4), their receptors (BMPR1A and BMPR2) as well as other signaling proteins like SMAD 1,4 and 5 that are involved in BMP signaling [55]. BMP4 was up-regulated in ZG and ZF compared to ZR. Further studies established a role for BMP4 in the regulation of androgen biosynthesis. BMP4 altered phosphorylation of SMADs and decreased the synthesis of C19 steroids (DHEA, DHEA-S and $\Delta 4 \mathrm{~A}$ ) in human adrenal H295R cells by suppressing CYP17 expression (Figure 4) [56]. Hence, transcriptome analysis has clearly enhanced our understanding of adrenal androgen production.

\subsection{Transcriptional profiling of human adrenal $\mathrm{NCl}-\mathrm{H} 295$ cells}

As mentioned earlier in this review, the $\mathrm{NCl}-\mathrm{H} 295$ cell model is almost the only available cell model to study human steroidogenesis [57]. It represents steroidogenesis of all three layers of the human adrenal cortex and has been shown to follow regulations similar to those seen in human biology $[57,58]$. For instance, ACTH/CAMP/PKA signaling plays an essential role in the regulation of steroid production of $\mathrm{H} 295 \mathrm{R}$ cells $[89,112,113]$, and regulation of CYP17, which is essential for human androgen production, seems similar in this cell system $[31,114]$.

Therefore, transcriptome profiling of H295A cells has been employed to identify specific kinases involved in the phosphorylation of CYP17, which is known to enhance 17,20 lyase activity for androgen production [67]. As it has been shown that CAMP promotes CYP17 phosphorylation [64], stimulation with cAMP on H295A cells was used to study the kinome with the Affymetrix U133 plus 2.0 chip, which provides full kinase coverage [67]. In H295A cells, 145 of the 278 known serine/threonine kinases were expressed, but only six showed significant differential expression (>2-fold) upon 8Br-cAMP treatment [67]. Although several kinases modulating pathways targeting CYP17 (e.g. PKA/PI3K/Akt, calcium/calmodulin/MAPK) were studied, none 
was found to enhances 17,20 lyase activity. ROCK1 kinase was shown to phosphorylate CYP17 but did not lead to increased 17,20 lyase activity [67]. Only recently the kinase promoting CYP17 phosphorylation and activity was identified as p38a (MAPK14) [68]. In theory, the network connecting this kinase to other regulators of androgen biosynthesis is currently drawn as follows (Figure 4): DENND1A, ROCK1, hormones or other factors activate mitogen-activated protein kinase kinase kinases (M3Ks), which trigger mitogen-activated protein kinases (such as MAP2K3, 4 or 6 ) that target p38 $\alpha$ and finally CYP17 [114]. However, confirmation and further details of this network are needed. Understanding of this network may uncover targets for diagnostic or therapeutic opportunities.

Similarly, we used transcriptome analysis of H295R cells grown under starvation conditions to study the regulation of human androgen biosynthesis [48]. Previously, we described that H295R cells produce more androgens than H295A cells [60], and that serum starvation of H295R cells leads to a marked shift towards androgen production (Figure 4A) [48, 61]. In starved H295R cells increased 17,20 lyase activity and decreased HSD3B2 expression and activity were found. These findings resemble some changes seen in the human adrenal during adrenarche $[77$, 115]. Therefore, we used our starvation model and performed gene expression profiling and bioinformatics analysis to identify novel regulatory genes and networks underlying androgen biosynthesis. Interestingly, only 14 genes were found significantly altered (>2.0-fold) after starvation [48]. As expected, genes involved in steroid biosynthetic processes (HSD3B1, HSD3B2 and CYP21A2), energy metabolism and signal transduction (especially MAPKK kinases) were identified. However, we also found two genes downregulated after starvation, namely retinoic acid receptor beta (RARB) and angiopoietin-like protein 1 (ANGPTL1), which were novel to the scene of androgen regulation [48].

According to GEO profiling, RARB is expressed in normal human adrenal and gonadal tissues (GEO GDS3113/109692/RARB). Our functional studies revealed that RARB regulates the promoters of StAR, CYP17 and HSD3B2 (Figure 4B) [48] , and that overexpression of RARB 
and its ligand all-trans retinoic acid (ATRA) enhance $\triangle 4 \mathrm{~A}$ production in starved $\mathrm{H} 295 \mathrm{R}$ cells (Figure 4C). We also found that RARB co-operates with transcription factor Nur77 for modulating HSD3B2. As Nur77 has been shown to play an essential role in the adrenal zonation [82] and in fetal developmental specific steroid production [81], the role of RARB relating to these events remains to be explored.

Depending on the cell context ANGPTL1 is a known regulator of angiogenesis or antiangiogenesis [116, 117]. In endothelial cells it exerts its anti-apoptotic activity by stimulating phosphorylation of ERK1/2 and Akt [117]. We found that ANGPTL1 induces ERK1/2 phosphorylation and represses CYP17 expression in starved H295R cells (Figure 4D and 4E). ERK regulation of CYP17 phosphorylation has been reported in several studies [69, 70]. When analyzing the transcriptome data of our starved H295R cell model with a cut-off level of $>1.5$-fold $(p<0.05), 77$ genes are differentially expressed; 60 are up- while 17 are downregulated. The corresponding heat map and analysis for gene ontology (GO) processes are shown in Figure 5. Details on enrichment analysis for GO pathways and disease biomarkers are given in Table 1. The table describes the statistical ranking of different pathways/disease biomarkers based on the $\mathrm{p}$-values. GO process analysis suggests an effect of serum starvation on steroidogenesis, MAPK signaling and on the regulation of cell differentiation. This is conceivable since serum contains several growth factors, cytokines and hormones, which are known to play an important role for cell differentiation.

Interestingly, our study also identified a network containing 7 genes, among them CYP21A2, for androgen regulation (Figure 6). CYP21A2 is important for cortisol production and its deficiency causes androgen excess in humans, also known as congenital adrenal hyperplasia $(\mathrm{CAH})$. The other genes were MEK kinase 5 (MAP3K5) also known as apoptosis signal-regulated kinase 1 (ASK1), thyroid stimulating hormone receptor (TSHR), glucosaminyl (N-Acetyl) transferase 1, core 2 (GCNT1, also known as G6NT), complement factor I (CFI, also known as factor 1), Serpin peptidase inhibitor, clade A (alpha-1 antiproteinase, antitrypsin) member 5 (SERPINA5, 
also known as Protein C inhibitor) and GPCRs (Figure 7). The center of this network consists of the transcription factor SP1, which regulates CYP21A2, and this regulation seems to be controlled by the kinase ASK1 (MAP3K5). In general, ASK1 activates MAP2K4 that activates cJun N-terminal kinase 1 (JNK1) [118], which then phosphorylates transcription factor SP1 [119]. Thus, androgen regulation may not only include the CYP21A2 gene in case of CAH caused by 21-hydroxylase deficiency, but this gene may also be a factor of the normal regulatory network.

\section{Future directions}

In the near future, use of additional high throughput techniques, including next generation sequencing (NGS), micro-RNA profiling, proteomics and metabolomics, will enhance our knowledge on human androgen biosynthesis in health and disease. Specifically, NGS will provide genetic diagnosis in patients who are not currently diagnosed. Most likely involvement of multiple genes/networks will be found explaining the different phenotypes of PCOS. MicroRNA studies may reveal novel regulatory modules for androgen production at the posttranscriptional level so far undiscovered. Micro-RNAs are predicted to influence 30 to $80 \%$ of human genes [120-124], hence it might be wise to consider a role of micro-RNAs in disorders of androgen production. With a phospho-proteomics approach proteins or pathways, which are modulated by phosphorylation, can be further studied in order to put the current knowledge on involvement of single phospho-regulated proteins in androgen production in a bigger perspective. Finally, metabolomics profiling shows consequences of regulatory mechanisms, and untargeted analysis of biomaterials using massspectrometric methods will allow detection of steroid metabolites unthought of, which will eventually lead to novel pathways as recently illustrated by the studies on the backdoor pathway. Ultimately, all this knowledge will help in finding and developing new diagnostic tools and drugs. These are especially needed for the treatment of PCOS, which affects almost $10 \%$ of women. 


\section{Acknowledgements}

We thank Balazs Legeza, Nesa Marti and Chantal Cripe Mamie for proofreading. The own work reviewed in this paper has been supported by grants of the Swiss National Science Foundation (320030-146127).

\section{Abbreviations}

AKR1C2/4, aldo-keto reductase family 1, member C2/4; ASK1, apoptosis signal-regulated kinase 1; ANGPTL1, angiopoietin-like protein 1; ATRA, all-trans-retinoic acid; BMPs, bone morphogenetic proteins; C9orf3, chromosome 9 open reading frame 3; $\mathrm{CRH}$, corticotropinreleasing hormone; CFI, complement factor I; CYB5, cytochrome b5; CYP19A1, aromatase; CYP21A2, 21-hydroxylase; DENND1A, DENN/MADD domain containing 1A; DHEA, dehydroepiandrosterone; DHEA-S, dehydroepiandrosterone sulfate; GCNT1, glucosaminyl (NAcetyl) transferase 1, core 2; GWAS, genome-wide association studies; HMGA2, high mobility group AT-hook 2; HSD3B, 3 $\beta$-hydroxysteroid dehydrogenase; HSD17B, $17 \beta$-hydroxysteroid dehydrogenase; INSR, insulin receptor; JNK/SAPK, c-Jun N-terminal kinases/stress-activated protein kinases; LH, luteinizing hormone; LHCGR, luteinizing hormone/choriogonadotropin receptor; LRH1, liver receptor homologue; MAPK14, mitogen-activated protein kinase 14; MC2R, melanocortin 2 receptor; NGFIB/Nur77, nerve growth factor IB; PCOS, polycystic ovary syndrome; PKA, protein kinase A; PKB/AKT, protein kinase B; PKC, protein kinase A; POR, P450 oxidoreductase; PP2A, protein phosphatase 2A; RAB5B, Ras-related protein Rab-5B; RARB, retinoic acid receptor beta; ROCK1, rho-associated, coiled-coil containing protein kinase 1; SERPINA5, Serpin peptidase inhibitor, clade A member 5 ; SF1, steroidogenic factor-1; SIP, steroidogenic-inducing protein; SRD5A, 5a-reductase; StAR, steroidogenic acute regulatory protein; SULT2A1, dehydroepaindrosterone sulfotransferase; SUMO1P1, SUMO1 pseudogene 1; THADA, thyroid adenoma associated; TOX3, TOX high mobility group box family member 3 ; 
TSHR, thyroid stimulating hormone receptor; YAP1, Yes-associated protein 1; ZNF217, zinc finger protein 217 ; ZF, zona fasciculata; ZR, zona reticularis;

\section{Figure Legends:}

Figure 1 - Scheme showing the classic and the alternative, backdoor pathway for the synthesis of dihydrotestosterone (DHT) from cholesterol. Intermediate products, enzymes and cofactors needed for the catalytic processes are depicted. Note that in the alternative pathway 17hydroxyprogesterone ( $17 \mathrm{OH}-\mathrm{Prog}$ ) is $5 \alpha, 3 \alpha$ reduced and then stepwise further converted to DHT without going through testosterone.

Figure 2 - Organ specificity of androgen biosynthesis. The classic androgen synthesis pathway, as established in the adrenal cortex, the human testis and ovary, and in peripheral tissues, such as the adipose tissue, is shown. The scheme shows the pathways starting from cholesterol as substrate and gives intermediate products as well as responsible enzymes and/or cofactors enabling the stepwise conversion for the production of testosterone. Organ specific characteristics are shown in colors: green, adrenal cortex; violet, ovarian theca cell; blue, testis Leydig cell; red, adipose tissue. Prog, progesterone; Preg, pregnenolone; DHEA, dehydroepiandrosterone; (DHEA-S), DHEA-sulfate; 17OH Preg, 17a-hydroxypregnenolone; 17OH P, 17-hydroxyprogesterone; 11DOC, 11-deoxycortisol; $\Delta 4 \mathrm{~A}$, androstenedione; E1, estrone; E2, estradiol; T, Testosterone.

Figure 3 - Signaling network of androgen production. Scheme summarizing published signaling pathways, regulating and regulated genes, proteins and co-factors. Newer genes and networks involved in the regulation of androgen biosynthesis are highlighted in yellow. GWAS of PCOS cohorts helped in discovering the recently described DENND1A gene [37, 38]. Overexpression 
of variant 2 of DENNDA1 in PCOS is responsible for augmented androgen production by altering the expression of CYP17A1 and CYP11A1. A possible mechanism how DENND1A (as transcription factor or via signaling) may alter the expression of steroid enzymes is shown in dotted lines [39]. Transcriptome profiling of adrenal cortex layers recently discovered differential expression of BMP4 between the zona glomerulosa and reticularis [56]. BMP4 phosphorylates SMADs and decreases androgen synthesis by suppressing CYP17A1 expression. The exact signaling between phospho-SMADs and CYP17A1 gene (dotted line) remains unknown. Transcriptome profiling of H295A cells revealed that ROCK1 kinase phosphorylates CYP17A1; however, this phosphorylation does not enhance 17,20 lyase activity [67]. Recent p38 $\alpha$ (MAPK14) was described to phosphorylate CYP17A1 and confer increased 17,20 lyase activity, which is essential for the production of androgens [68]. It has been suggested that ROCK1 regulates MAPK signaling (dotted line) and targets p38a for CYP17 phosphorylation [68]. Several studies show crosstalk pathways between MAPK signaling (especially MAPK kinase p38) and SMADs signaling (dotted line) [125, 126]. Gene expression profiling of starved, hyperandrogenic H295R cells revealed a role for two novel gene networks around RARB and ANGPTL1 for androgen production [48]. Transcription factor RARB stimulates the StAR, CYP17 and HSD3B2 promoters. Secretory protein ANGPTL1 modulates CYP17 expression by inducing ERK $1 / 2$ phosphorylation.

Figure 4 - Impact of serum starvation on human adrenal H295R cells and the role of RARB and ANGPTL1 regulators for adrenal androgen biosynthesis. A) Serum starvation induces a hyperandrogenic state in H295R cells. A steroid profile (thin layer chromatogram) of H295R cells grown under starvation growth condition (SM) for $48 \mathrm{~h}$ is shown in comparison to the profile obtained under normal growth conditions (GM). Quantitative analysis is shown on the right. For Materials and Methods see [48]. ${ }^{*} p<0.05,{ }^{* *} p<0.01$. Prog, progesterone; $\triangle 4 A$, androstenedione; Preg, pregnenolone; DHEA, dehydroepiandrosterone; 17OH Preg, 17a- 
hydroxypregnenolone; 17OH Prog, 17-hydroxyprogesterone; 11DOC, 11-deoxycortisol. B) Role of the nuclear transcription factor RARB in altering HSD3B2 gene expression. H295R cells were transfected with the human $-1.05 \mathrm{~kb}$ HSD3B2 promoter construct along with an expression vector for the RARB transcription factor in the presence or absence of ATRA. Promoter activation was assessed by the dual luciferase assay (Promega) [48]. ${ }^{*} p<0.05,{ }^{* *} p<0.01 . C$ ) Effect of RARB overexpression and ATRA treatment on H295R steroidogenesis. H295R cells were transiently transfected with RARB and optionally treated with $1 \mu \mathrm{M}$ ATRA. Steroid production was assessed as described in [48]. Quantitative data for androstenedione $(\Delta 4 \mathrm{~A})$ are depicted. ${ }^{*} p<0.05,{ }^{* *} p<0.01$. D) Role of ANGPTL1 in androgen production. Effect of rANGPTL1 on ERK1/2 kinase phosphorylation and on CYP17 expression is shown (Western blots from [48]). E) Scheme showing the suggested interplay between ANGPTL1, ERK phosphorylation and inhibition of CYP17 expression.

Figure 5 - Heat Map of Affymetrix microarray data showing differentially expressed genes in H295R cells grown under normal versus hyperandrogenic starvation conditions. Microarray data were analyzed by Cluster 3.0 and JTreeview software for creating a representative heat map of the 77 genes, which were identified at a significance level of $>1.5$ fold change. In the heat map graphic, rows show individual genes. Gene expression levels are displayed for each independent sample. In the picture we also show the analysis for GO processes for the identified genes, like the regulation of cell differentiation, response to steroid hormones, steroid biosynthetic process and MAPKKK cascade. Over-expression is shown in red, underexpression in green.

Figure 6 - Network analysis of differentially expressed genes ( $>1.5$ fold change) in starvation conditions. GeneGo Metacore software was used for analyzing the microarray data to obtain common gene networks between significantly changed genes. Networks found for analyzing at 
$>2.0$ fold change are published in [48]. Seven genes can be found in an additional common network when analyzing at >1.5 fold change, namely CYP21A2, ASK1 (MAP3K5), TSHR, G6NT (GCNT1), complement factor 1 (CF1), protein C inhibitor (SERPINA5) and GPCRs like GPR56.

The center of this network consists of the transcription factor SP1, which seems to regulate CYP21A2, and this regulation seems to be controlled by ASK1 (MAP3K5) kinase. The core of the identified network is highlighted in grey color. Only down-regulated genes were found in this network and they are marked with small red circles. Green lines show activating relationships; red lines show inhibition; gray lines show relationships of unknown quality; turquoise bold lines connect members of the RAS superfamily.

\section{References:}

[1] Miller WL, Auchus RJ. The molecular biology, biochemistry, and physiology of human steroidogenesis and its disorders. Endocrine reviews. 2011;32:81-151.

[2] Davison SL, Bell R. Androgen physiology. Seminars in reproductive medicine. 2006;24:71-7. [3] Arlt W. Androgen therapy in women. Eur J Endocrinol. 2006;154:1-11.

[4] Wilson JD, Auchus RJ, Leihy MW, Guryev OL, Estabrook RW, Osborn SM, et al. 5alphaandrostane-3alpha,17beta-diol is formed in tammar wallaby pouch young testes by a pathway involving 5alpha-pregnane-3alpha,17alpha-diol-20-one as a key intermediate. Endocrinology. $2003 ; 144: 575-80$.

[5] Wilson JD, Shaw G, Leihy ML, Renfree MB. The marsupial model for male phenotypic development. Trends in endocrinology and metabolism: TEM. 2002;13:78-83.

[6] Auchus RJ. The backdoor pathway to dihydrotestosterone. Trends Endocrin Met. $2004 ; 15: 432-8$ 
[7] Fluck CE, Tajima T, Pandey AV, Arlt W, Okuhara K, Verge CF, et al. Mutant P450 oxidoreductase causes disordered steroidogenesis with and without Antley-Bixler syndrome. Nature genetics. 2004;36:228-30.

[8] Homma K, Hasegawa T, Nagai T, Adachi M, Horikawa R, Fujiwara I, et al. Urine steroid hormone profile analysis in cytochrome P450 oxidoreductase deficiency: implication for the backdoor pathway to dihydrotestosterone. The Journal of clinical endocrinology and metabolism. 2006;91:2643-9.

[9] Kamrath C, Hochberg Z, Hartmann MF, Remer T, Wudy SA. Increased activation of the alternative "backdoor" pathway in patients with 21-hydroxylase deficiency: evidence from urinary steroid hormone analysis. The Journal of clinical endocrinology and metabolism. 2012;97:E367-75.

[10] Fluck CE, Meyer-Boni M, Pandey AV, Kempna P, Miller WL, Schoenle EJ, et al. Why boys will be boys: two pathways of fetal testicular androgen biosynthesis are needed for male sexual differentiation. American journal of human genetics. 2011;89:201-18.

[11] Biason-Lauber A, Miller WL, Pandey AV, Fluck CE. Of marsupials and men: "Backdoor" dihydrotestosterone synthesis in male sexual differentiation. Molecular and cellular endocrinology. 2013;371:124-32.

[12] Fluck CE, Miller WL, Auchus RJ. The 17, 20-lyase activity of cytochrome p450c17 from human fetal testis favors the delta5 steroidogenic pathway. The Journal of clinical endocrinology and metabolism. 2003;88:3762-6.

[13] Fevold HR, Lorence MC, McCarthy JL, Trant JM, Kagimoto M, Waterman MR, et al. Rat P450(17 alpha) from testis: characterization of a full-length cDNA encoding a unique steroid hydroxylase capable of catalyzing both delta 4- and delta 5-steroid-17,20-lyase reactions. Mol Endocrinol. 1989;3:968-75. 
[14] Mathieu AP, Auchus RJ, LeHoux JG. Comparison of the hamster and human adrenal P450c17 (17 alpha-hydroxylase/17,20-lyase) using site-directed mutagenesis and molecular modeling. The Journal of steroid biochemistry and molecular biology. 2002;80:99-107.

[15] Tremblay Y, Fleury A, Beaudoin C, Vallee M, Belanger A. Molecular cloning and expression of guinea pig cytochrome P450c17 cDNA (steroid 17 alpha-hydroxylase/17,20 lyase): tissue distribution, regulation, and substrate specificity of the expressed enzyme. DNA and cell biology. 1994;13:1199-212.

[16] Hess RA. Estrogen in the adult male reproductive tract: a review. Reproductive biology and endocrinology : RB\&E. 2003;1:52.

[17] Puurunen J, Piltonen T, Jaakkola P, Ruokonen A, Morin-Papunen L, Tapanainen JS. Adrenal androgen production capacity remains high up to menopause in women with polycystic ovary syndrome. The Journal of clinical endocrinology and metabolism. 2009;94:1973-8.

[18] de Ronde W, Hofman A, Pols HA, de Jong FH. A direct approach to the estimation of the origin of oestrogens and androgens in elderly men by comparison with hormone levels in postmenopausal women. Eur J Endocrinol. 2005;152:261-8.

[19] de Ronde W, van der Schouw YT, Muller M, Grobbee DE, Gooren LJ, Pols HA, et al. Associations of sex-hormone-binding globulin (SHBG) with non-SHBG-bound levels of testosterone and estradiol in independently living men. The Journal of clinical endocrinology and metabolism. 2005;90:157-62.

[20] Havelock JC, Auchus RJ, Rainey WE. The rise in adrenal androgen biosynthesis: adrenarche. Seminars in reproductive medicine. 2004;22:337-47.

[21] Xing Y, Lerario AM, Rainey W, Hammer GD. Development of adrenal cortex zonation. Endocrinology and metabolism clinics of North America. 2015;44:243-74.

[22] Best B. DHEA Hormone Replacement. 1990.

[23] Rege J, Rainey WE. The steroid metabolome of adrenarche. The Journal of endocrinology. 2012;214:133-43. 
[24] Miller WL, Flück CE. CHAPTER 13 - Adrenal cortex and its disorders. In: Sperling MA, editor. Pediatric Endocrinology (FOURTH EDITION): Content Repository Only!; 2014. p. 471532.e1.

[25] Nguyen AD, Conley AJ. Adrenal androgens in humans and nonhuman primates: production, zonation and regulation. Endocrine development. 2008;13:33-54.

[26] Ibanez L, de Zegher F, Potau N. Premature pubarche, ovarian hyperandrogenism, hyperinsulinism and the polycystic ovary syndrome: from a complex constellation to a simple sequence of prenatal onset. Journal of endocrinological investigation. 1998;21:558-66.

[27] Rosenfield RL. Clinical review: Identifying children at risk for polycystic ovary syndrome. The Journal of clinical endocrinology and metabolism. 2007;92:787-96.

[28] Labrie F. Intracrinology. Molecular and cellular endocrinology. 1991;78:C113-8.

[29] Slominski A, Zbytek B, Nikolakis G, Manna PR, Skobowiat C, Zmijewski M, et al. Steroidogenesis in the skin: implications for local immune functions. The Journal of steroid biochemistry and molecular biology. 2013;137:107-23.

[30] Dhayat NA, Frey AC, Frey BM, d'Uscio CH, Vogt B, Rousson V, et al. Estimation of reference curves for the urinary steroid metabolome in the first year of life in healthy children: tracing the complexity of human postnatal steroidogenesis. The Journal of steroid biochemistry and molecular biology. 2015.

[31] Fluck CE, Pandey AV. Steroidogenesis of the testis -- new genes and pathways. Annales d'endocrinologie. 2014;75:40-7.

[32] Malikova J, Fluck CE. Novel insight into etiology, diagnosis and management of primary adrenal insufficiency. Hormone research in paediatrics. 2014;82:145-57.

[33] Ehrmann DA. Polycystic ovary syndrome. The New England journal of medicine. 2005;352:1223-36. 
[34] Carmina E, Koyama T, Chang L, Stanczyk FZ, Lobo RA. Does Ethnicity Influence the Prevalence of Adrenal Hyperandrogenism and Insulin Resistance in Polycystic-OvarySyndrome. American journal of obstetrics and gynecology. 1992;167:1807-12.

[35] Bulun SE. CHAPTER 17 - Physiology and Pathology of the Female Reproductive Axis. In: Kronenberg SMSPRLM, editor. Williams Textbook of Endocrinology (Twelfth Edition). Philadelphia: Content Repository Only!; 2011. p. 581-660.

[36] Bargiota A, Diamanti-Kandarakis E. The effects of old, new and emerging medicines on metabolic aberrations in PCOS. Therapeutic advances in endocrinology and metabolism. 2012;3:27-47.

[37] Chen ZJ, Zhao H, He L, Shi Y, Qin Y, Li Z, et al. Genome-wide association study identifies susceptibility loci for polycystic ovary syndrome on chromosome 2p16.3, 2p21 and 9q33.3. Nature genetics. 2011;43:55-9.

[38] Shi Y, Zhao H, Cao Y, Yang D, Li Z, Zhang B, et al. Genome-wide association study identifies eight new risk loci for polycystic ovary syndrome. Nature genetics. 2012;44:1020-5.

[39] McAllister JM, Modi B, Miller BA, Biegler J, Bruggeman R, Legro RS, et al. Overexpression of a DENND1A isoform produces a polycystic ovary syndrome theca phenotype. Proc Natl Acad Sci U S A. 2014;111:E1519-27.

[40] Kahsar-Miller MD, Nixon C, Boots LR, Go RC, Azziz R. Prevalence of polycystic ovary syndrome (PCOS) in first-degree relatives of patients with PCOS. Fertil Steril. 2001;75:53-8.

[41] Recabarren SE, Sir-Petermann T, Rios R, Maliqueo M, Echiburu B, Smith R, et al. Pituitary and testicular function in sons of women with polycystic ovary syndrome from infancy to adulthood. The Journal of clinical endocrinology and metabolism. 2008;93:3318-24.

[42] Liu DM, Torchen LC, Sung Y, Paparodis R, Legro RS, Grebe SK, et al. Evidence for gonadotrophin secretory and steroidogenic abnormalities in brothers of women with polycystic ovary syndrome. Hum Reprod. 2014;29:2764-72. 
[43] Franks S. Can Animal Models of PCOS Help Point the Way Towards Early and Effective Therapeutic Intervention in Women With the Syndrome? Endocrinology. 2015;156:2371-3.

[44] Gilling-Smith C, Willis DS, Beard RW, Franks S. Hypersecretion of androstenedione by isolated thecal cells from polycystic ovaries. The Journal of clinical endocrinology and metabolism. 1994;79:1158-65.

[45] McAllister JM, Kerin JF, Trant JM, Estabrook RW, Mason Jl, Waterman MR, et al. Regulation of cholesterol side-chain cleavage and 17 alpha-hydroxylase/lyase activities in proliferating human theca interna cells in long term monolayer culture. Endocrinology. 1989;125:1959-66.

[46] Havelock JC, Rainey WE, Carr BR. Ovarian granulosa cell lines. Molecular and cellular endocrinology. 2004;228:67-78.

[47] Breckwoldt M, Selvaraj N, Aharoni D, Barash A, Segal I, Insler V, et al. Expression of Ad4$\mathrm{BP} /$ cytochrome P450 side chain cleavage enzyme and induction of cell death in long-term cultures of human granulosa cells. Molecular human reproduction. 1996;2:391-400.

[48] Udhane SS, Pandey AV, Hofer G, Mullis PE, Fluck CE. Retinoic acid receptor beta and angiopoietin-like protein 1 are involved in the regulation of human androgen biosynthesis. Scientific reports. 2015;5:10132.

[49] Brock BJ, Waterman MR. Biochemical differences between rat and human cytochrome P450c17 support the different steroidogenic needs of these two species. Biochemistry. 1999;38:1598-606.

[50] Le Goascogne C, Sananes N, Gouezou M, Takemori S, Kominami S, Baulieu EE, et al. Immunoreactive cytochrome P-450(17 alpha) in rat and guinea-pig gonads, adrenal glands and brain. Journal of reproduction and fertility. 1991;93:609-22.

[51] Arlt W, Martens JW, Song M, Wang JT, Auchus RJ, Miller WL. Molecular evolution of adrenarche: structural and functional analysis of p450c17 from four primate species. Endocrinology. 2002;143:4665-72. 
[52] Abbott DH, Bird IM. Nonhuman primates as models for human adrenal androgen production: function and dysfunction. Reviews in endocrine \& metabolic disorders. 2009;10:3342.

[53] Rainey WE, Carr BR, Sasano H, Suzuki T, Mason JI. Dissecting human adrenal androgen production. Trends in endocrinology and metabolism: TEM. 2002;13:234-9.

[54] Wang W, Yang L, Suwa T, Casson PR, Hornsby PJ. Differentially expressed genes in zona reticularis cells of the human adrenal cortex. Molecular and cellular endocrinology. $2001 ; 173: 127-34$

[55] Rege J, Nakamura Y, Wang T, Merchen TD, Sasano H, Rainey WE. Transcriptome profiling reveals differentially expressed transcripts between the human adrenal zona fasciculata and zona reticularis. The Journal of clinical endocrinology and metabolism. 2014;99:E518-27.

[56] Rege J, Nishimoto KH, Nishimoto K, Rodgers RJ, Auchus RJ, Rainey WE. Bone morphogenetic protein-4 (BMP4): A paracrine regulator of human adrenal C steroid synthesis. Endocrinology. 2015:en20141942.

[57] Rainey WE, Saner K, Schimmer BP. Adrenocortical cell lines. Molecular and cellular endocrinology. 2004;228:23-38.

[58] Gazdar AF, Oie HK, Shackleton CH, Chen TR, Triche TJ, Myers CE, et al. Establishment and characterization of a human adrenocortical carcinoma cell line that expresses multiple pathways of steroid biosynthesis. Cancer research. 1990;50:5488-96.

[59] Rodriguez H, Hum DW, Staels B, Miller WL. Transcription of the human genes for cytochrome P450scc and P450c17 is regulated differently in human adrenal NCI-H295 cells than in mouse adrenal $\mathrm{Y} 1$ cells. The Journal of clinical endocrinology and metabolism. $1997 ; 82: 365-71$.

[60] Samandari E, Kempna P, Nuoffer JM, Hofer G, Mullis PE, Fluck CE. Human adrenal corticocarcinoma NCl-H295R cells produce more androgens than $\mathrm{NCl}-\mathrm{H} 295 \mathrm{~A}$ cells and differ in 
3beta-hydroxysteroid dehydrogenase type 2 and 17,20 lyase activities. The Journal of endocrinology. 2007;195:459-72.

[61] Kempna P, Hirsch A, Hofer G, Mullis PE, Fluck CE. Impact of differential P450c17 phosphorylation by CAMP stimulation and by starvation conditions on enzyme activities and androgen production in NCl-H295R cells. Endocrinology. 2010;151:3686-96.

[62] Yanagibashi K, Hall PF. Role of electron transport in the regulation of the lyase activity of C21 side-chain cleavage P-450 from porcine adrenal and testicular microsomes. J Biol Chem. 1986;261:8429-33.

[63] Auchus RJ, Lee TC, Miller WL. Cytochrome b5 augments the 17,20-lyase activity of human P450c17 without direct electron transfer. J Biol Chem. 1998;273:3158-65.

[64] Zhang LH, Rodriguez H, Ohno S, Miller WL. Serine phosphorylation of human P450c17 increases 17,20-lyase activity: implications for adrenarche and the polycystic ovary syndrome. Proc Natl Acad Sci U S A. 1995;92:10619-23.

[65] Wang YH, Tee MK, Miller WL. Human cytochrome p450c17: single step purification and phosphorylation of serine 258 by protein kinase a. Endocrinology. 2010;151:1677-84 .

[66] Pandey AV, Mellon SH, Miller WL. Protein phosphatase 2A and phosphoprotein SET regulate androgen production by P450c17. J Biol Chem. 2003;278:2837-44.

[67] Tee MK, Dong Q, Miller WL. Pathways leading to phosphorylation of p450c17 and to the posttranslational regulation of androgen biosynthesis. Endocrinology. 2008;149:2667-77.

[68] Tee MK, Miller WL. Phosphorylation of human cytochrome P450c17 by p38alpha selectively increases 17,20 lyase activity and androgen biosynthesis. The Journal of biological chemistry. 2013;288:23903-13.

[69] Nelson-Degrave VL, Wickenheisser JK, Hendricks KL, Asano T, Fujishiro M, Legro RS, et al. Alterations in mitogen-activated protein kinase kinase and extracellular regulated kinase signaling in theca cells contribute to excessive androgen production in polycystic ovary syndrome. Mol Endocrinol. 2005;19:379-90. 
[70] Kempna P, Hofer G, Mullis PE, Fluck CE. Pioglitazone inhibits androgen production in NClH295R cells by regulating gene expression of CYP17 and HSD3B2. Molecular pharmacology. 2007;71:787-98.

[71] Yin L, Hu Q. CYP17 inhibitors--abiraterone, C17,20-lyase inhibitors and multi-targeting agents. Nature reviews Urology. 2014;11:32-42.

[72] Attard G, Reid AH, Yap TA, Raynaud F, Dowsett M, Settatree S, et al. Phase I clinical trial of a selective inhibitor of CYP17, abiraterone acetate, confirms that castration-resistant prostate cancer commonly remains hormone driven. Journal of clinical oncology : official journal of the American Society of Clinical Oncology. 2008;26:4563-71.

[73] Simard J, Ricketts ML, Gingras S, Soucy P, Feltus FA, Melner MH. Molecular biology of the 3beta-hydroxysteroid dehydrogenase/delta5-delta4 isomerase gene family. Endocrine reviews. 2005;26:525-82.

[74] Wang L, Salavaggione E, Pelleymounter L, Eckloff B, Wieben E, Weinshilboum R. Human 3beta-hydroxysteroid dehydrogenase types 1 and 2: Gene sequence variation and functional genomics. The Journal of steroid biochemistry and molecular biology. 2007;107:88-99.

[75] Sauer LA, Chapman JC, Dauchy RT. Topology of 3 beta-hydroxy-5-ene-steroid dehydrogenase/delta 5-delta 4-isomerase in adrenal cortex mitochondria and microsomes. Endocrinology. 1994;134:751-9.

[76] Doody KM, Carr BR, Rainey WE, Byrd W, Murry BA, Strickler RC, et al. 3 betahydroxysteroid dehydrogenase/isomerase in the fetal zone and neocortex of the human fetal adrenal gland. Endocrinology. 1990;126:2487-92.

[77] Gell JS, Carr BR, Sasano H, Atkins B, Margraf L, Mason JI, et al. Adrenarche results from development of a 3beta-hydroxysteroid dehydrogenase-deficient adrenal reticularis. The Journal of clinical endocrinology and metabolism. 1998;83:3695-701. 
[78] Nelson VL, Legro RS, Strauss JF, 3rd, McAllister JM. Augmented androgen production is a stable steroidogenic phenotype of propagated theca cells from polycystic ovaries. Mol Endocrinol. 1999;13:946-57.

[79] Udhane S, Kempna P, Hofer G, Mullis PE, Fluck CE. Differential regulation of human 3beta-hydroxysteroid dehydrogenase type 2 for steroid hormone biosynthesis by starvation and cyclic AMP stimulation: studies in the human adrenal $\mathrm{NCl}-\mathrm{H} 295 \mathrm{R}$ cell model. Plos One. 2013;8:e68691.

[80] Rainey WE, Nakamura Y. Regulation of the adrenal androgen biosynthesis. The Journal of steroid biochemistry and molecular biology. 2008;108:281-6.

[81] Goto M, Piper Hanley K, Marcos J, Wood PJ, Wright S, Postle AD, et al. In humans, early cortisol biosynthesis provides a mechanism to safeguard female sexual development. The Journal of clinical investigation. 2006;116:953-60.

[82] Bassett MH, Suzuki T, Sasano H, De Vries CJ, Jimenez PT, Carr BR, et al. The orphan nuclear receptor NGFIB regulates transcription of 3beta-hydroxysteroid dehydrogenase. implications for the control of adrenal functional zonation. J Biol Chem. 2004;279:37622-30.

[83] Pawlak KJ, Prasad M, Thomas JL, Whittal RM, Bose HS. Inner mitochondrial translocase Tim50 interacts with 3beta-hydroxysteroid dehydrogenase type 2 to regulate adrenal and gonadal steroidogenesis. J Biol Chem. 2011;286:39130-40.

[84] Prasad M, Thomas JL, Whittal RM, Bose HS. Mitochondrial 3beta-hydroxysteroid dehydrogenase enzyme activity requires reversible $\mathrm{pH}$-dependent conformational change at the intermembrane space. J Biol Chem. 2012;287:9534-46.

[85] Stocco DM, Wang X, Jo Y, Manna PR. Multiple signaling pathways regulating steroidogenesis and steroidogenic acute regulatory protein expression: more complicated than we thought. Mol Endocrinol. 2005;19:2647-59. 
[86] Kempna P, Marti N, Udhane S, Fluck CE. Regulation of androgen biosynthesis - A short review and preliminary results from the hyperandrogenic starvation $\mathrm{NCl}-\mathrm{H} 295 \mathrm{R}$ cell model. Molecular and cellular endocrinology. 2015;408:124-32.

[87] Simpson ER, Waterman MR. Regulation of the synthesis of steroidogenic enzymes in adrenal cortical cells by ACTH. Annual review of physiology. 1988;50:427-40.

[88] Mesiano S, Jaffe RB. Developmental and functional biology of the primate fetal adrenal cortex. Endocrine reviews. 1997;18:378-403.

[89] Sewer MB, Waterman MR. ACTH modulation of transcription factors responsible for steroid hydroxylase gene expression in the adrenal cortex. Microsc Res Tech. 2003;61:300-7.

[90] Pearson G, Robinson F, Beers Gibson T, Xu BE, Karandikar M, Berman K, et al. Mitogenactivated protein (MAP) kinase pathways: regulation and physiological functions. Endocrine reviews. 2001;22:153-83.

[91] Sewer MB, Waterman MR. CAMP-dependent protein kinase enhances CYP17 transcription via MKP-1 activation in H295R human adrenocortical cells. J Biol Chem. 2003;278:8106-11.

[92] Lin T, Wang D, Hu J, Stocco DM. Upregulation of human chorionic gonadotrophin-induced steroidogenic acute regulatory protein by insulin-like growth factor-I in rat Leydig cells. Endocrine. 1998;8:73-8.

[93] Diamanti-Kandarakis E, Piperi C, Spina J, Argyrakopoulou G, Papanastasiou L, Bergiele A, et al. Polycystic ovary syndrome: the influence of environmental and genetic factors. Hormones (Athens). 2006;5:17-34.

[94] Vink JM, Sadrzadeh S, Lambalk CB, Boomsma DI. Heritability of polycystic ovary syndrome in a Dutch twin-family study. The Journal of clinical endocrinology and metabolism. 2006;91:2100-4.

[95] Baillargeon JP, Carpentier AC. Brothers of women with polycystic ovary syndrome are characterised by impaired glucose tolerance, reduced insulin sensitivity and related metabolic defects. Diabetologia. 2007;50:2424-32. 
[96] Goodarzi MO, Jones MR, Li X, Chua AK, Garcia OA, Chen YD, et al. Replication of association of DENND1A and THADA variants with polycystic ovary syndrome in European cohorts. Journal of medical genetics. 2012;49:90-5.

[97] Louwers YV, Stolk L, Uitterlinden AG, Laven JS. Cross-ethnic meta-analysis of genetic variants for polycystic ovary syndrome. The Journal of clinical endocrinology and metabolism. 2013;98:E2006-12.

[98] Strauss JF, 3rd, McAllister JM, Urbanek M. Persistence pays off for PCOS gene prospectors. The Journal of clinical endocrinology and metabolism. 2012;97:2286-8.

[99] Welt CK, Styrkarsdottir U, Ehrmann DA, Thorleifsson G, Arason G, Gudmundsson JA, et al. Variants in DENND1A are associated with polycystic ovary syndrome in women of European ancestry. The Journal of clinical endocrinology and metabolism. 2012;97:E1342-7.

[100] Eriksen MB, Nielsen MF, Brusgaard K, Tan Q, Andersen MS, Glintborg D, et al. Genetic alterations within the DENND1A gene in patients with polycystic ovary syndrome (PCOS). Plos One. 2013;8:e77186.

[101] McAllister JM, Legro RS, Modi BP, Strauss JF, 3rd. Functional genomics of PCOS: from GWAS to molecular mechanisms. Trends in endocrinology and metabolism: TEM. 2015;26:11824.

[102] Lostroh AJ. Regulation by FSH and ICSH (LH) of reproductive function in the immature male rat. Endocrinology. 1969;85:438-45.

[103] Hillier SG. Current concepts of the roles of follicle stimulating hormone and luteinizing hormone in folliculogenesis. Hum Reprod. 1994;9:188-91.

[104] Ballester J, Munoz MC, Dominguez J, Rigau T, Guinovart JJ, Rodriguez-Gil JE. Insulindependent diabetes affects testicular function by FSH- and LH-linked mechanisms. Journal of andrology. 2004;25:706-19.

[105] Chang RJ, Cook-Andersen H. Disordered follicle development. Molecular and cellular endocrinology. 2013;373:51-60. 
[106] Jawhar NM. Tissue Microarray: A rapidly evolving diagnostic and research tool. Annals of Saudi medicine. 2009;29:123-7.

[107] Endoh A, Kristiansen SB, Casson PR, Buster JE, Hornsby PJ. The zona reticularis is the site of biosynthesis of dehydroepiandrosterone and dehydroepiandrosterone sulfate in the adult human adrenal cortex resulting from its low expression of 3 beta-hydroxysteroid dehydrogenase. The Journal of clinical endocrinology and metabolism. 1996;81:3558-65.

[108] Romero DG, Plonczynski MW, Welsh BL, Gomez-Sanchez CE, Zhou MY, GomezSanchez EP. Gene expression profile in rat adrenal zona glomerulosa cells stimulated with aldosterone secretagogues. Physiological genomics. 2007;32:117-27.

[109] Nishimoto K, Rigsby CS, Wang T, Mukai K, Gomez-Sanchez CE, Rainey WE, et al. Transcriptome analysis reveals differentially expressed transcripts in rat adrenal zona glomerulosa and zona fasciculata. Endocrinology. 2012;153:1755-63.

[110] Baba T, Otake H, Sato T, Miyabayashi K, Shishido Y, Wang CY, et al. Glycolytic genes are targets of the nuclear receptor Ad4BP/SF-1. Nature communications. 2014;5:3634.

[111] Bird IM. In the zone: understanding zona reticularis function and its transformation by adrenarche. The Journal of endocrinology. 2012;214:109-11.

[112] Richards JS. New signaling pathways for hormones and cyclic adenosine 3',5'monophosphate action in endocrine cells. Mol Endocrinol. 2001;15:209-18.

[113] Gallo-Payet N, Payet MD. Mechanism of action of ACTH: beyond cAMP. Microsc Res Tech. 2003;61:275-87.

[114] Miller WL, Tee MK. The post-translational regulation of 17,20 lyase activity. Molecular and cellular endocrinology. 2015;408:99-106.

[115] Miller WL. Androgen synthesis in adrenarche. Reviews in endocrine \& metabolic disorders. 2009;10:3-17. 
[116] Dhanabal M, LaRochelle WJ, Jeffers M, Herrmann J, Rastelli L, McDonald WF, et al. Angioarrestin: an antiangiogenic protein with tumor-inhibiting properties. Cancer research. 2002;62:3834-41.

[117] Kubota Y, Oike Y, Satoh S, Tabata Y, Niikura Y, Morisada T, et al. Cooperative interaction of Angiopoietin-like proteins 1 and 2 in zebrafish vascular development. Proc Natl Acad Sci U S A. $2005 ; 102: 13502-7$.

[118] Matsukawa J, Matsuzawa A, Takeda K, Ichijo H. The ASK1-MAP kinase cascades in mammalian stress response. Journal of biochemistry. 2004;136:261-5.

[119] Chuang JY, Wang YT, Yeh SH, Liu YW, Chang WC, Hung JJ. Phosphorylation by c-Jun $\mathrm{NH} 2$-terminal kinase 1 regulates the stability of transcription factor Sp1 during mitosis. Molecular biology of the cell. 2008;19:1139-51.

[120] John B, Enright AJ, Aravin A, Tuschl T, Sander C, Marks DS. Human MicroRNA targets. PLoS biology. 2004;2:e363.

[121] Rajewsky N, Socci ND. Computational identification of microRNA targets. Developmental biology. 2004;267:529-35.

[122] Brennecke J, Stark A, Russell RB, Cohen SM. Principles of microRNA-target recognition. PLoS biology. 2005;3:e85.

[123] Grun D, Wang YL, Langenberger D, Gunsalus KC, Rajewsky N. microRNA target predictions across seven Drosophila species and comparison to mammalian targets. Plos Comput Biol. 2005;1:e13.

[124] Krek A, Grun D, Poy MN, Wolf R, Rosenberg L, Epstein EJ, et al. Combinatorial microRNA target predictions. Nature genetics. 2005;37:495-500.

[125] Saika S. TGFbeta pathobiology in the eye. Laboratory investigation; a journal of technical methods and pathology. 2006;86:106-15. 
[126] Rodrigues Diez R, Rodrigues-Diez R, Lavoz C, Rayego-Mateos S, Civantos E, RodriguezVita J, et al. Statins inhibit angiotensin II/Smad pathway and related vascular fibrosis, by a TGFbeta-independent process. Plos One. 2010;5:e14145. 
Table 1: Identification of 77 differentially expressed genes in hyperandrogenic human adrenal H295R cells.

Gene expression microarray analysis was performed on human adrenal H295R cells grown under normal growth (GM) vs hyperandrogenic, starvation (SM) conditions. Analysis with a fold change cut-off at 1.5 (with an adjusted p-value of $<0.05$ ) revealed 77 gene transcripts that were differentially expressed. Enrichment analysis was then performed with GeneGo MetaCore software to assess the biological function of the identified genes; this included gene involvement in different signaling pathways and diseases states. Results provided in the table are grouped according to biological processes. Analysis significance levels ( $p$-values) and false discovery rate (FDR) are given. $\mathrm{N}$ means the number of genes found in the specific group.

\begin{tabular}{|c|c|c|c|c|c|}
\hline \multicolumn{2}{|r|}{ Enrichment analysis } & \multicolumn{4}{|c|}{ GM vs SM *xls (>1.5 fold analysis) } \\
\hline & Pathway Maps & $\mathrm{p}$-value & FDR & $\mathrm{N}$ & Genes \\
\hline 1 & $\begin{array}{l}\text { Cortisol biosynthesis from } \\
\text { cholesterol }\end{array}$ & 1.317E-04 & 1.040E-02 & 3 & $\begin{array}{c}\text { HSD3B2, CYP21A2, } \\
\text { HSD3B1 }\end{array}$ \\
\hline 2 & $\begin{array}{l}\text { Neurophysiological processes, } \\
\text { circadian rhythm }\end{array}$ & $1.012 \mathrm{E}-02$ & $1.928 \mathrm{E}-01$ & 2 & DEC2, DEC1 (Stra13) \\
\hline 3 & $\begin{array}{l}\text { Androstenedione and } \\
\text { testosterone biosynthesis and } \\
\text { metabolism }\end{array}$ & $1.274 \mathrm{E}-02$ & $1.928 \mathrm{E}-01$ & 2 & HSD3B2, HSD3B1 \\
\hline 4 & $\begin{array}{l}\text { Development, role of proteases } \\
\text { in hematopoietic stem cell } \\
\text { mobilization }\end{array}$ & 5.707E-02 & 1.960E-01 & 1 & Carboxypeptidase M \\
\hline 5 & $\begin{array}{l}\text { Apoptosis and survival, NO } \\
\text { signaling in apoptosis; oxidative } \\
\text { stress, role of ASK1 under } \\
\text { oxidative stress }\end{array}$ & 7.236E-02 & 1.960E-01 & 1 & ASK1 (MAP3K5) \\
\hline 6 & $\begin{array}{l}\text { Immune response, IFN } \\
\text { alpha/beta signaling pathway }\end{array}$ & 7.538E-02 & $1.960 \mathrm{E}-01$ & 1 & IRF9 \\
\hline 7 & $\begin{array}{l}\text { Transcription, transcription } \\
\text { regulation of amino acid } \\
\text { metabolism }\end{array}$ & 7.840E-02 & $1.960 \mathrm{E}-01$ & 1 & ASSY \\
\hline 8 & $\begin{array}{l}\text { Signal transduction, Erk } \\
\text { interactions: inhibition of Erk }\end{array}$ & $1.051 \mathrm{E}-01$ & 1.960E-01 & 1 & MKP-3 \\
\hline 9 & $\begin{array}{l}\text { Transcription, role of the non- } \\
\text { genomic action of retinoic acid } \\
\text { and phosphorylation of retinoic } \\
\text { acid receptors in the initiation of } \\
\text { transcription }\end{array}$ & $1.051 \mathrm{E}-01$ & $1.960 \mathrm{E}-01$ & 1 & RARbeta \\
\hline 10 & Cell adhesion, PLAU signaling & 1.197E-01 & $1.960 \mathrm{E}-01$ & 1 & SERPINA5 \\
\hline & $\begin{array}{l}\text { Diseases } \\
\text { (by biomarkers) }\end{array}$ & $p$-value & FDR & & Genes \\
\hline 1 & Endocrine system diseases & 3.839E-07 & $2.221 \mathrm{E}-04$ & 38 & $\begin{array}{c}\text { FHL2, ANGPTL1, } \\
\text { HSD3B2, KLRG1, } \\
\text { NELL2, ERM, } \\
\text { DOCK4, CYP21A2, } \\
\text { Plastin, hASH1, MKP. } \\
\text { 3, PLK2, Apo- }\end{array}$ \\
\hline
\end{tabular}




\begin{tabular}{|c|c|c|c|c|c|}
\hline & & & & & $\begin{array}{l}\text { 2L(TNFSF10), OLR1, } \\
\text { ASK1 (MAP3K5), } \\
\text { ASSY, Kv4.2 channel, } \\
\text { NOV, IGFBP7, } \\
\text { UNC5B, RNS2, } \\
\text { CD22, RARbeta, } \\
\text { GPR56, HSD3B1, } \\
\text { SERPINA5, } \\
\text { Neurotrimin, DEC1 } \\
\text { (Stra13), CCDC80, } \\
\text { FAP, TR-beta1, } \\
\text { LAPTM4B, NPTX2, } \\
\text { Nidogen-2, KCNK2 }\end{array}$ \\
\hline 2 & Gonadal disorders & 2.407E-05 & 3.567E-03 & 24 & $\begin{array}{l}\text { FHL2, HSD3B2, ERM, } \\
\text { DOCK4, CYP21A2, } \\
\text { Plastin, MKP-3, PLK2, } \\
\text { Apo-2L(TNFSF10), } \\
\text { IGFBP7/8, UNC5B, } \\
\text { RNS2, CD22, } \\
\text { RARbeta, GPR56, } \\
\text { HSD3B1, SERPINA5, } \\
\text { FAP, TR-beta1, } \\
\text { Thyroid hormone } \\
\text { receptor, LAPTM4B, } \\
\text { Nidogen-2, KCNK2 }\end{array}$ \\
\hline 3 & Ovarian diseases & 5.123E-05 & 4.316E-03 & 23 & $\begin{array}{l}\text { FHL2, ERM, DOCK4, } \\
\text { CYP21A2, Plastin, } \\
\text { MKP-3, PLK2, Apo- } \\
\text { 2L(TNFSF10), } \\
\text { IGFBP7, UNC5B, } \\
\text { RNS2, CD22, RAR, } \\
\text { RARbeta, GPR56, } \\
\text { HSD3B1, SERPINA5, } \\
\text { FAP, TR-beta1, } \\
\text { Thyroid hormone } \\
\text { receptor, LAPTM4B, } \\
\text { Nidogen-2, KCNK2 }\end{array}$ \\
\hline 4 & Ovarian neoplasms & 2.695E-04 & 1.015E-02 & 21 & $\begin{array}{l}\text { FHL2, ERM, DOCK4, } \\
\text { Plastin, MKP-3, PLK2, } \\
\text { Apo-2L(TNFSF10), } \\
\text { IGFBP7, UNC5B, } \\
\text { RNS2, CD22, } \\
\text { RARbeta, GPR56, } \\
\text { SERPINA5, TR-beta1, } \\
\text { Thyroid hormone } \\
\text { receptor, LAPTM4B, } \\
\text { Nidogen-2, KCNK2 }\end{array}$ \\
\hline 5 & Female genital diseases & 1.263E-02 & 8.197E-02 & 50 & $\begin{array}{c}\text { FHL2, HSD3B2, } \\
\text { SLC9A2, ERM, } \\
\text { DOCK4, OLFML2B, }\end{array}$ \\
\hline
\end{tabular}




\begin{tabular}{|c|c|c|c|c|c|}
\hline & & & & & $\begin{array}{l}\text { G6NT, CYP21A2, } \\
\text { ABCA5, Zimp10, } \\
\text { Plastin, SLC1A3, } \\
\text { MKP-3, MKP-5, PLK2, } \\
\text { Apo-2L(TNFSF10), } \\
\text { ASK1 (MAP3K5), } \\
\text { Factor I, ASSY, Kv4.2 } \\
\text { channel, NOV, } \\
\text { IGFBP7, IGFBP7, } \\
\text { UNC5B, RNS2, } \\
\text { Trp53inp2, CD22, } \\
\text { RARbeta, BY55, } \\
\text { GRP-R, GPR56, } \\
\text { TRIB2, HSD3B1, } \\
\text { SERPINA5, } \\
\text { Neurotrimin, } \\
\text { C1orf192, DEC1 } \\
\text { (Stra13), CCDC80, } \\
\text { ARHGAP20, FAP, } \\
\text { NR3A, TR-beta1, } \\
\text { LAPTM4B, PGM2L1, } \\
\text { SV2B, Nidogen-2, } \\
\text { KCNK2, SVEP1 }\end{array}$ \\
\hline 6 & Hyperandrogenism & $5.559 \mathrm{E}-03$ & $5.454 \mathrm{E}-02$ & 2 & HSD3B2, CYP21A2 \\
\hline 7 & Male genital diseases & $3.223 \mathrm{E}-04$ & $1.015 \mathrm{E}-02$ & 46 & $\begin{array}{c}\text { FHL2, HSD3B2, } \\
\text { NELL2, Lphn3, } \\
\text { SLC9A2, ERM, } \\
\text { OLFML2B, G6NT, } \\
\text { CYP21A2, Zimp10, } \\
\text { Plastin, hASH1, } \\
\text { CCDC3, MKP-5, } \\
\text { PLK2, Apo- } \\
\text { 2L(TNFSF10), ASK1 } \\
\text { (MAP3K5), CFI, } \\
\text { ASSY, Kv4.2 channel, } \\
\text { IGFBP7, UNC5B, } \\
\text { Carboxypeptidase M, } \\
\text { ENC1, CD22, } \\
\text { RARbeta, GRP-R, } \\
\text { GPR56, TRIB2, } \\
\text { HSD3B1, SERPINA5, } \\
\text { CRMP4, Neurotrimin, } \\
\text { C1 orf192, CCDC80, } \\
\text { ARHGAP20, FAP, } \\
\text { TR-beta1, PGM2L1, } \\
\text { NPTX2, SV2B, } \\
\text { Nidogen-2, SVEP1 } \\
\end{array}$ \\
\hline 8 & Disorders of sex development & $3.420 \mathrm{E}-04$ & 1.015E-02 & 4 & $\begin{array}{l}\text { HSD3B2, CYP21A2, } \\
\text { GPR56, HSD3B1 }\end{array}$ \\
\hline
\end{tabular}




\begin{tabular}{|c|c|c|c|c|c|}
\hline 9 & Precocious puberty & $1.596 \mathrm{E}-04$ & $7.867 \mathrm{E}-03$ & 3 & $\begin{array}{c}\text { HSD3B2, CYP21A2, } \\
\text { GPR56 }\end{array}$ \\
\hline 10 & Small cell carcinoma & $8.748 \mathrm{E}-05$ & $5.982 \mathrm{E}-03$ & 5 & $\begin{array}{c}\text { hASH1, RAR, } \\
\text { RARbeta, GRP-R, } \\
\text { GPR56 }\end{array}$ \\
\hline
\end{tabular}


Cholesterol

CYP11A1

StAR

Pregnenolone

CYP17A1

170H-Preg $\stackrel{H S D 3 B 2}{\longrightarrow} 170 \mathrm{OH}-\mathrm{Prog} \stackrel{S R D 5 A 1}{\longrightarrow} 170 \mathrm{H}-\mathrm{DHP} \stackrel{A K R 1 C 2 / 4}{\stackrel{\text { (red) }}{\longrightarrow} 170 \mathrm{H}-A l l o}$

CYP17A1

CYB5

HSD3B2

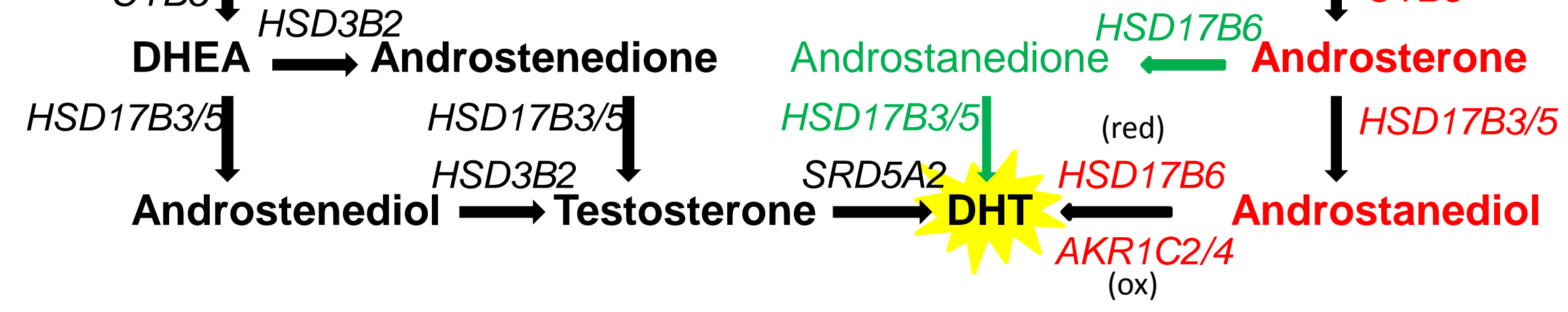

Classic Pathway

Alternative Backdoor Pathway 


\section{Adrenal Cortex}

Ovary Theca Cell

Testis Leydig Cell

\section{Peripheral Tissues}

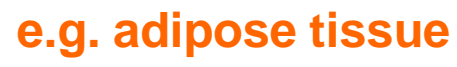

E1

个 CYP19A1

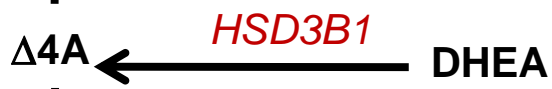

$\downarrow$ HSD17B5

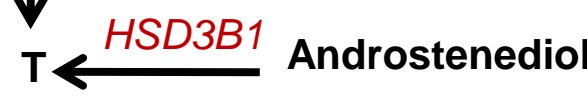

$\downarrow$ CYP19A1

E2

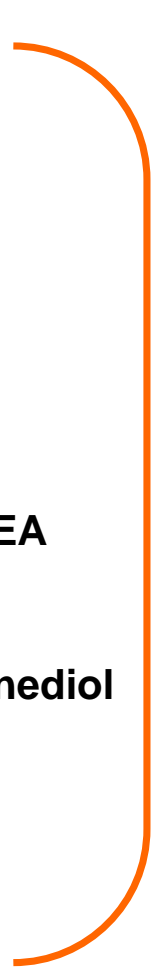

Cholesterol

StAR

$\downarrow C Y P 11 A 1$

Preg ............... Prog $\longrightarrow \rightarrow \rightarrow$ Aldosterone

CYP17A1

HSD3B2

CYP21A2

170HPreg......$+170 H P \longrightarrow 11 \mathrm{DOC} \rightarrow$ Cortisol

CYP17A1

$\downarrow P O R / b 5$

DHEA ................ $\rightarrow \triangle 4 A \stackrel{H S D 17 B 5}{\stackrel{H S D 17 B 3}{H}}$

$\checkmark \vee H S D 17 B 5$

Androstenediol HSD3B2

Testosterone

SULT2A1

DHEA-S

DHEA/-S, Androstenediol, $\triangle 4 \mathrm{~A}, \mathrm{~T}$

Circulation 


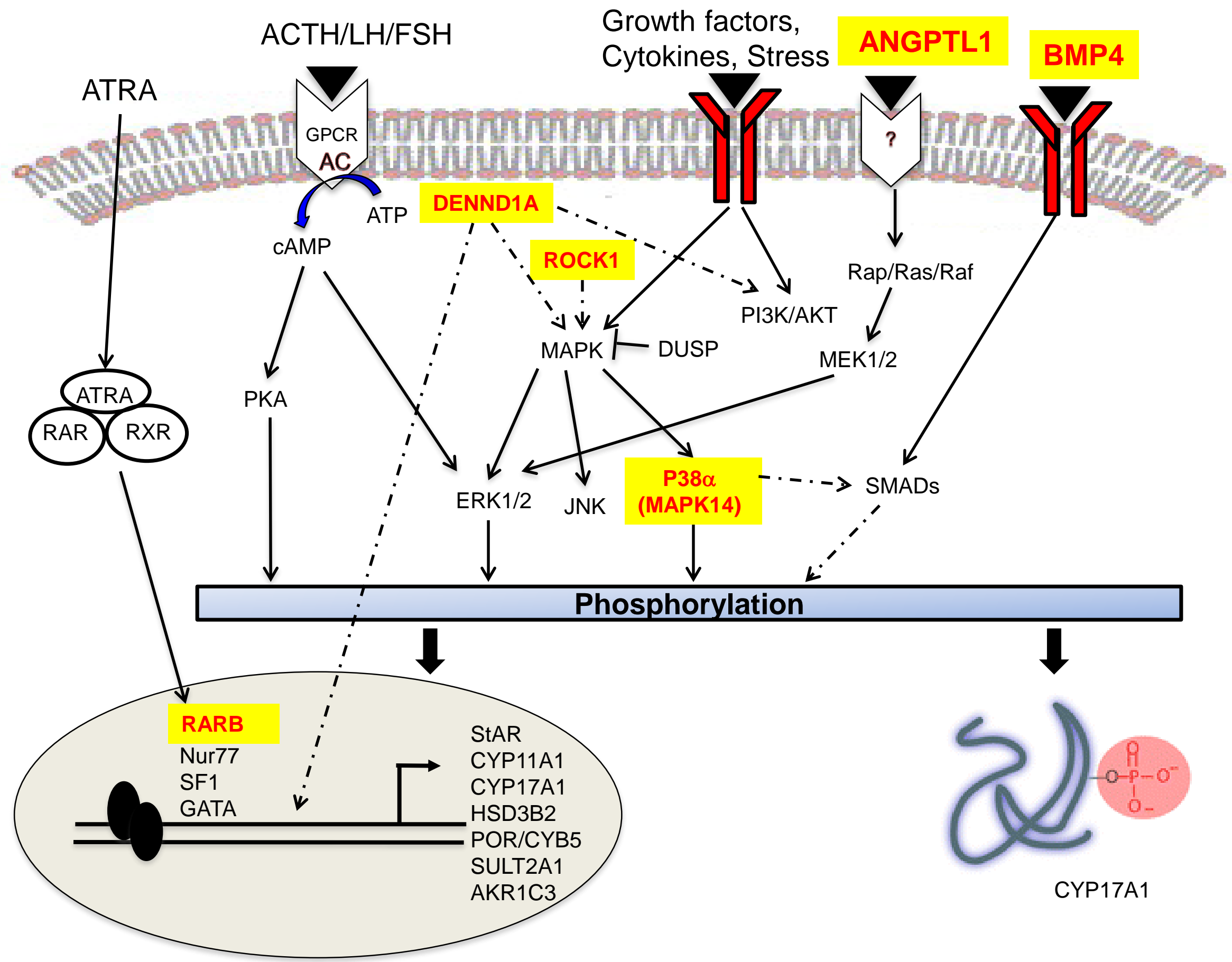


A

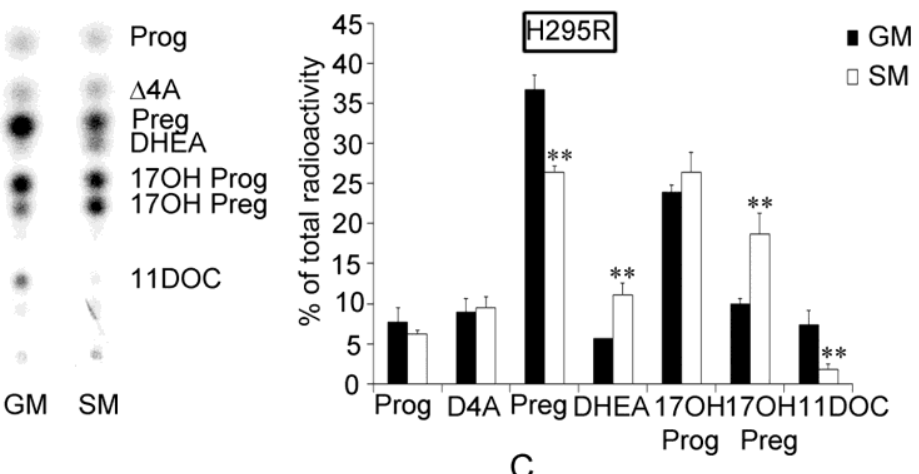

B

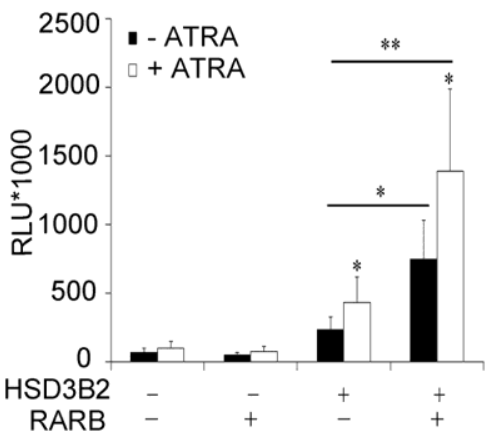

D

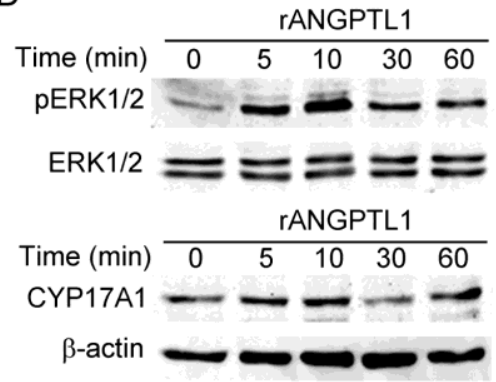

C

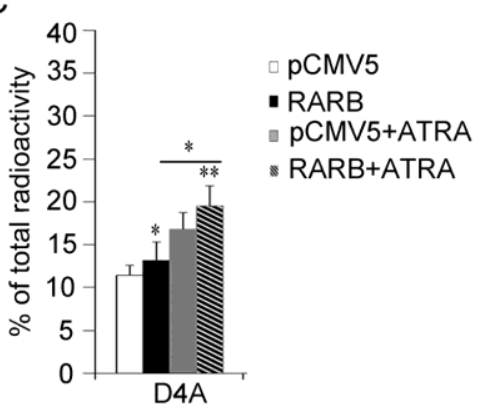

E

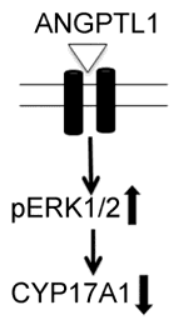




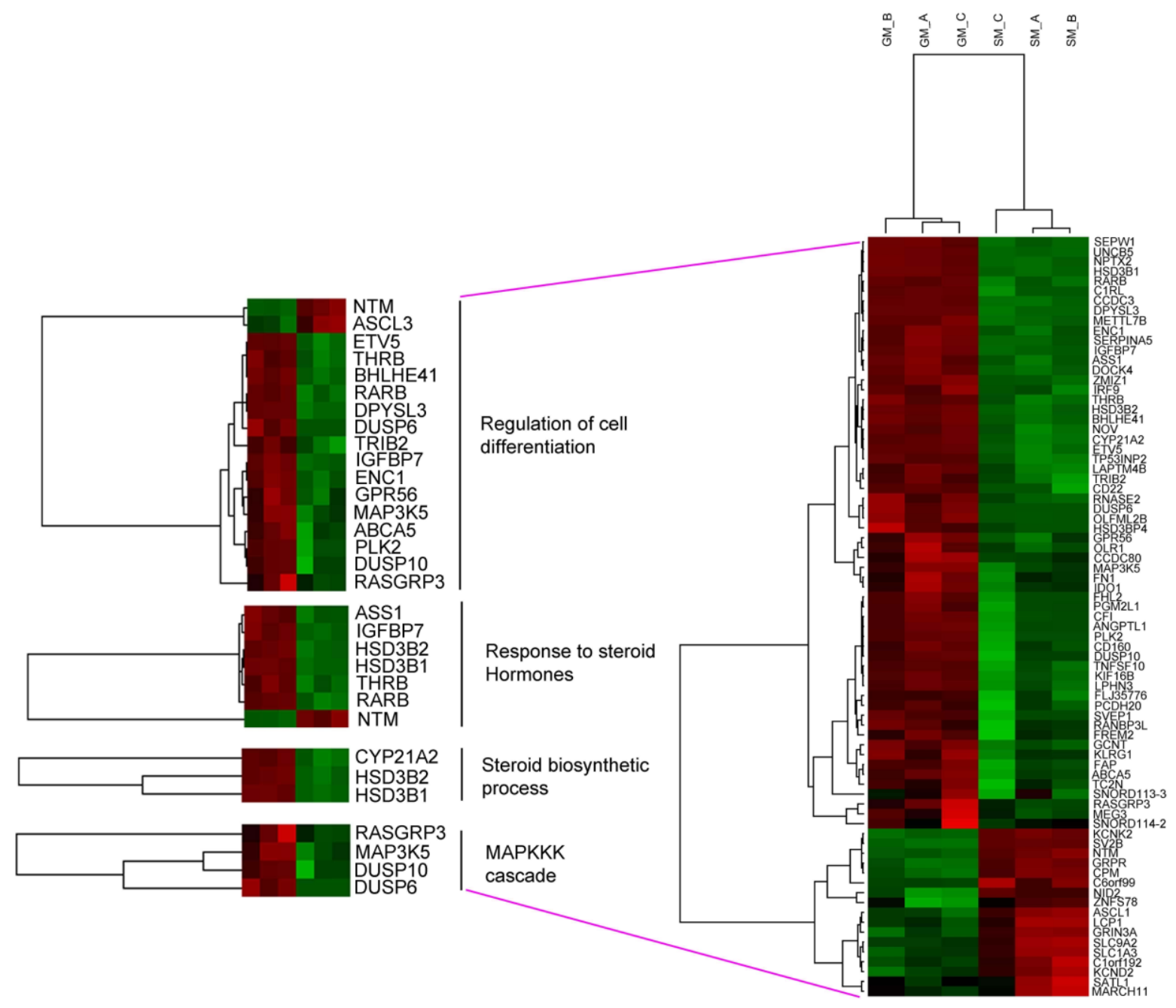




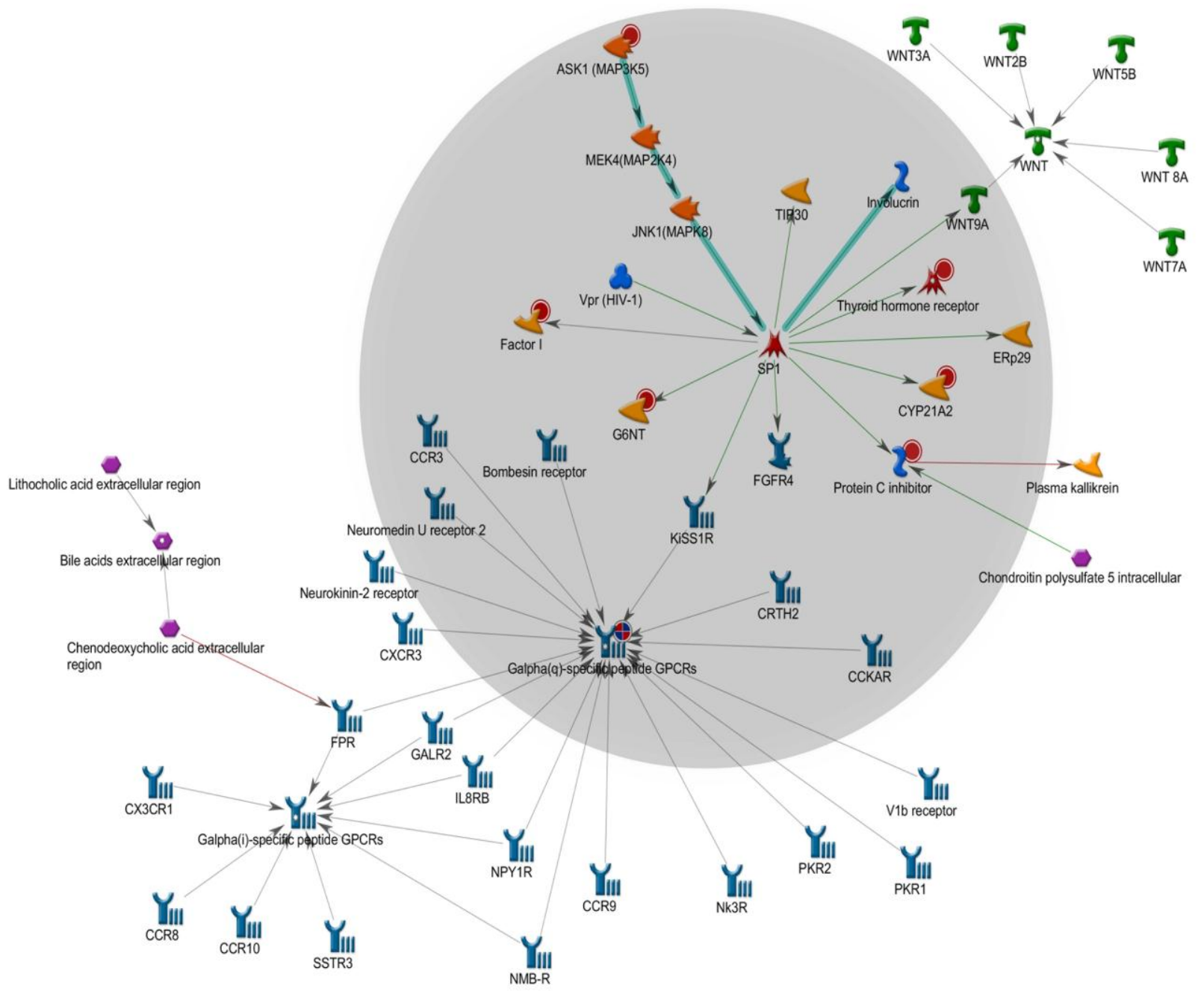




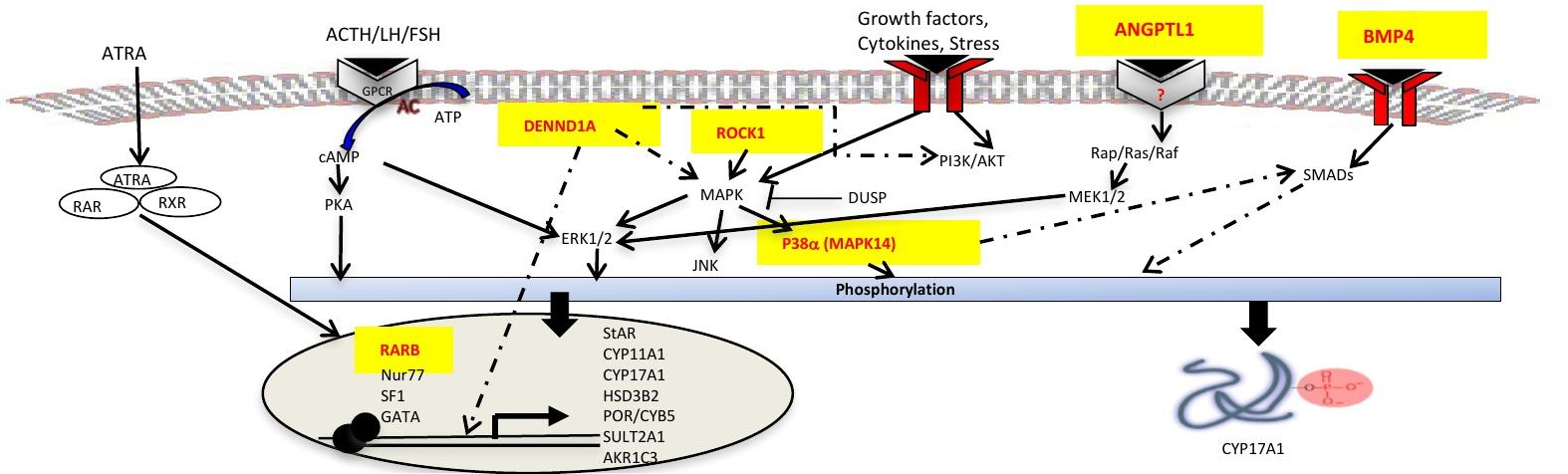

